Materials Science and Technology Division

CRADA Final Report

For CRADA Number ORNL0601.01

\title{
Modeling and Optimization of Direct Chill Casting to Reduce Ingot Cracking*
}

$\begin{array}{cc}\text { Subodh K. Das } & \text { Kozo Saito } \\ \text { Shridas Ningileri } & \text { Marwan Khraisheh } \\ \text { Zhengdong Long } & \text { Mohamed H. Hassan } \\ \text { Secat, Inc. } & \text { Kazunori Kuwana } \\ & \text { University of Kentucky } \\ \text { Qingyou Han } & \\ \text { S. Viswanathan } & \text { John Clark } \\ \text { Adrian Sabau } & \text { Albany Research Center } \\ \text { Oak Ridge National } & \text { John Hyrn } \\ \text { Laboratory } & \text { Argonne National } \\ & \text { Laboratory }\end{array}$

Date Published - August 2006

Prepared by the OAK RIDGE NATIONAL LABORATORY

Oak Ridge, Tennessee 37831

Managed by UT-BATTELLE, LLC

For the

U.S. Department of Energy

Under Contract DE-AC05-00OR22725

\begin{abstract}
APPROVED FOR PUBLIC RELEASE UNLIMITED DISTRIBUTION
\end{abstract}




\section{DOCUMENT AVAILABILITY}

Reports produced after January 1, 1996, are generally available free via the U.S. Department of Energy (DOE) Information Bridge.

Web site http:/Www.osti.gov/bridge

Reports produced before January 1, 1996, may be purchased by members of the pubiic from the following source.

National Technical Information Service

5285 Port Royal Road

Springfield, VA 22161

Telephone 703-605-6000 (1-800-553-6847)

TDD 703-487-4639

Fax 703-605-6900

E-mail info@ntis.fedworld.gov

Web site http://www.ntis.gov/support/ordernowabout.htm

Reports are available to DOE employees, DOE contractors, Energy Technology Data Exchange (ETDE) representatives, and International Nuclear Information System (INIS)

representatives from the following source.

Office of Scientific and Technical Information

P.O. Box 62

Oak Ridge, TN 37831

Telephone 865-576-8401

Fax 865-576-5728

E-mail reports@adonis.osti.gov

Web site http:/www.osti.govicontact.htm!

This report was prepared as an account of work sponsored by an agency of the United States Government. Neither the United States Government nor any agency thereof, nor any of their employees, makes any warranty, express or implied, or assumes any legal liability or responsibility for the accuracy, completeness, or usefulness of any information, apparatus, product, or process disclosed, or represents that its use would not infringe privately owned rights. Reference herein to any specific commercial product, process, or service by trade name, trademark, manufacturer, or otherwise, does not necessarily constitute or imply its endorsement, recommendation, or favoring by the United States Government or any agency thereof. The views and opinions of authors expressed herein do not necessarily state or reflect those of the United States Government or any agency thereof. 
Final Report Certification

for

CRADA Number 0000601

MULT - $\triangle 0-$ SECAT - 01

Between

UT-Battelle, LLC

and

Secat, Inc.

(Participant)

Instructions:

Mark the appropriate statement in 1a or 1b below with an "IX." Refer to the articles in the CRADA terms and conditions governing the identification and marking of Protected CRADA Information (PCl).

If no $\mathrm{PCl}$ is identified, the report will be distributed without restriction. If $\mathrm{PCl}$ is identified, the report distribution will be limited in accordance with the CRADA terms and conditions governing release of data. In all cases items 2 and 3 must be true. That is, the report cannot contain Proprietary Information and a disclosure must be filed prior to release of the report.

This certification may either be made by using this form or may be made on company letterhead if the Participant desires. A faxed copy of this completed form is acceptable.

The following certification is made for the subject final report:

1. (a) $\square$ The final report contains information that qualifies as "Protected CRADA Information" (PCl). The $\mathrm{PCl}$ legend is printed on the report cover, and the $\mathrm{PCl}$ is clearly identified.

OR

(b) $X$ The final report does not contain "Protected CRADA Information." The "Approved for Public Release" legend is printed on the report cover.

2. The final report does not contain Proprietary Information.

3. By the signature below, the Participant has no objection to the public distribution of the final report due to patentable information.

For the Participant:

Jodd Bogaes

(Name)

Business Manager

(Title)

$8-3-06$

(Date) 
C/ORNL0601.01

Materials Science and Technology Division

CRADA Final Report

for CRADA Number ORNL0601.01

\section{Modeling and Optimization of Direct Chill Casting to Reduce Ingot Cracking*}

\author{
Subodh K. Das \\ Shridas Ningileri \\ Zhengdong Long \\ Secat, Inc. \\ Qingyou Han \\ S. Viswanathan \\ Adrian Sabau \\ Oak Ridge National Laboratory
}

\author{
Kozo Saito \\ Marwan Khraisheh \\ Mohamed H. Hassan \\ Kazunori Kuwana \\ University of Kentucky \\ John Clark \\ Albany Research Center \\ John Hyrn \\ Argonne National Laboratory
}

Date Published - August, 2006

Prepared by the

OAK RIDGE NATIONAL LABORATORY

Oak Ridge, Tennessee 37831 managed by

UT-BATTELLE, LLC

for the

U.S. Department of Energy

under Contract DE-AC05-00OR22725

APPROVED FOR PUBLIC RELEASE

UNLIMITED DISTRIBUTION

* This work was supported through a CRADA with Secat Inc., sponsored by the U.S. Department of Energy, Assistant Secretary for Energy Efficiency and Renewable Energy, Industrial Technologies Program, under contract DE-AC05-00OR22725 with UT-Battelle, LLC. 


\section{TABLE OF CONTENTS}

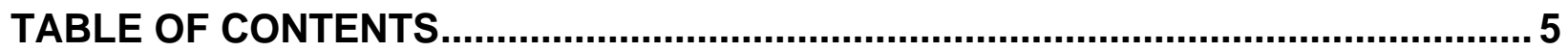

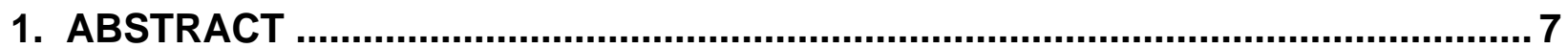

2. STATEMENT OF OBJECTIVES ........................................................................... 8

3. BENEFITS TO THE FUNDING DOE OFFICE'S MISSION .................................. 10

4. TECHNICAL DISCUSSION OF WORK PERFORMED BY ALL PARTIES .............. 10

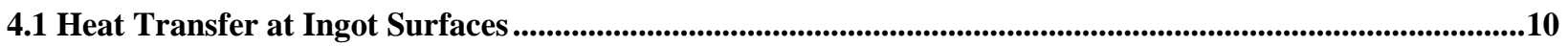

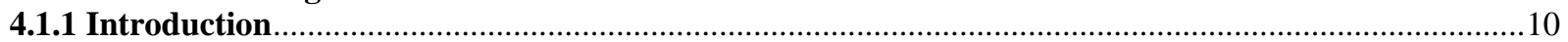

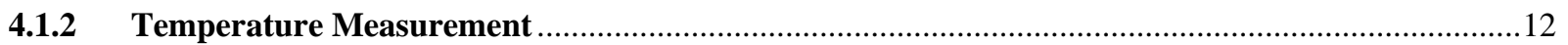

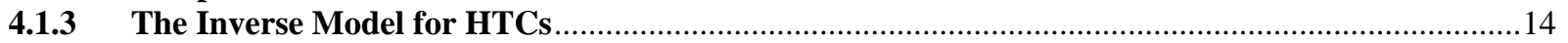

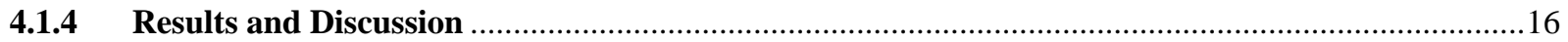

4.2. Nature and Formation of Surface Cracks in DC Cast Ingots.......................................................................18

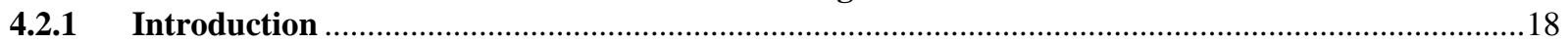

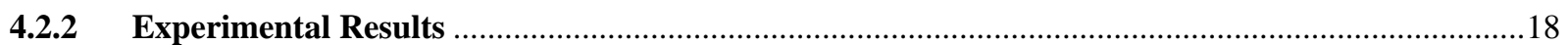

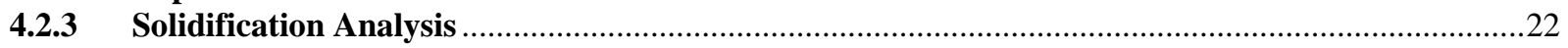

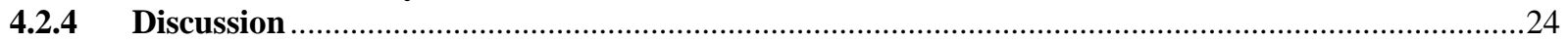

4.3 Mechanical Properties in the Nonequilibrium Mushy Zone of Alloys.......................................................25

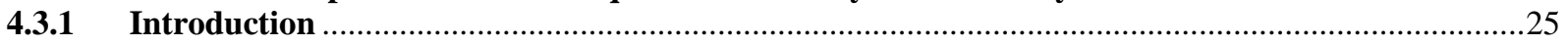

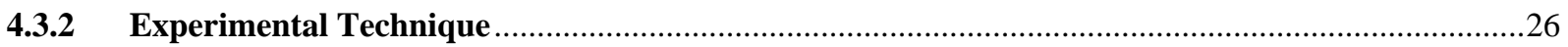

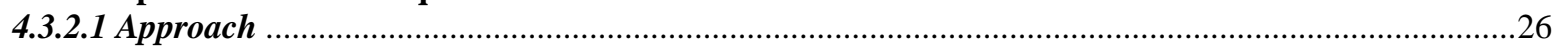

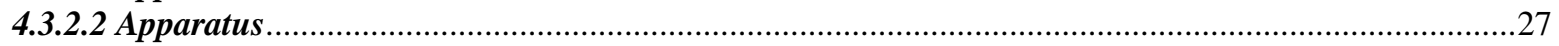

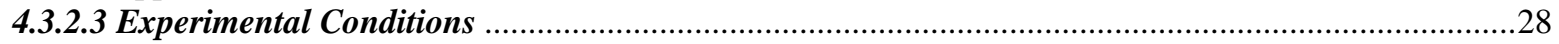

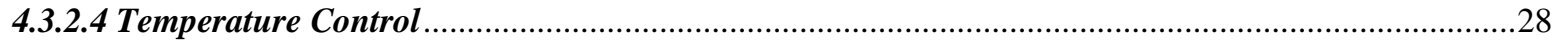

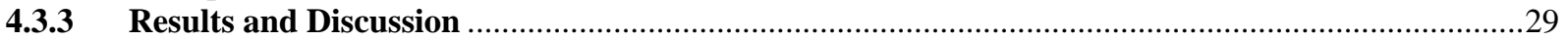

4.4. Constitutive Models for Aluminum Alloy at High Temperatures...........................................................33

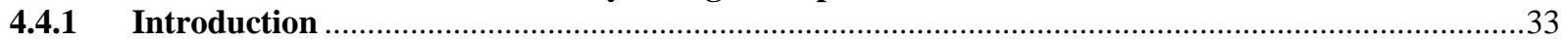

4.4.2 Model Calibration from Experimental Data for 3004 .....................................................................34

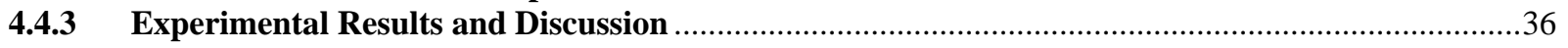

4.5. Modeling of Solidification and Stress-Strain Formation during DC Casting ..................................................39

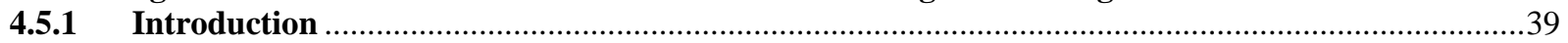

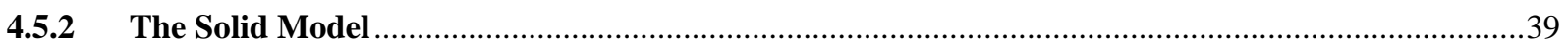

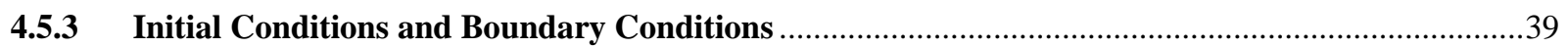

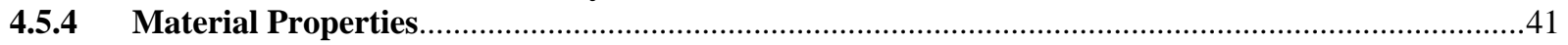

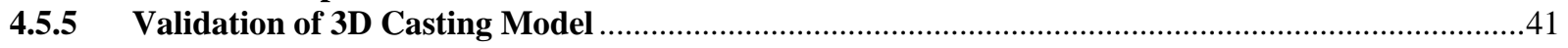

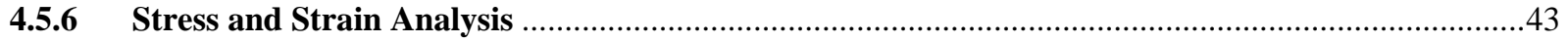

4.6. Prediction of Ingot Cracking Propensity ................................................................................................................46

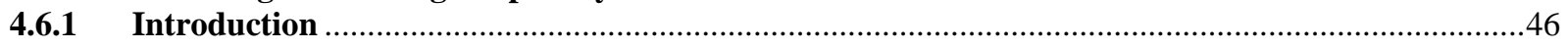

4.6.2 Ingot Cracking Propensity Based on Stress-Strain Simulation .......................................................46

4.6.3 Hot Tearing Susceptibility: Thermodynamic Predictions …….......................................................49

4.6.3.1 Background . 
4.6.3.2 Theory

4.6.3.3 Industrial Data Analysis

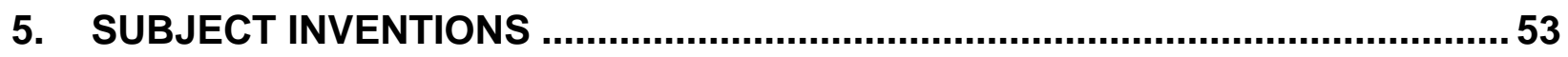

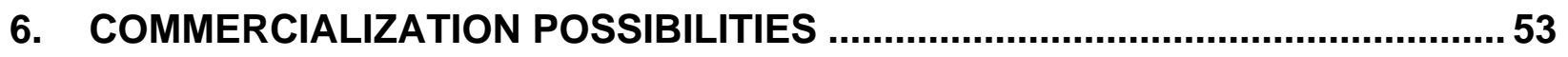

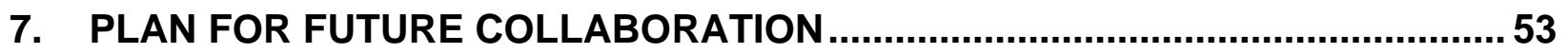

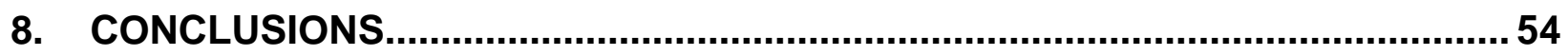

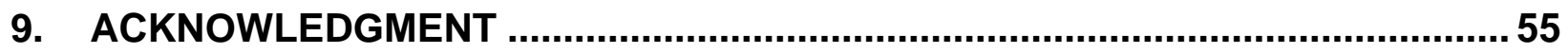

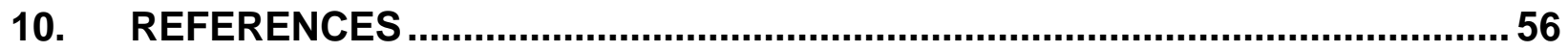

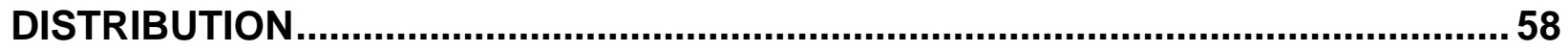

Internal Distribution .....................................................................................................................................................58

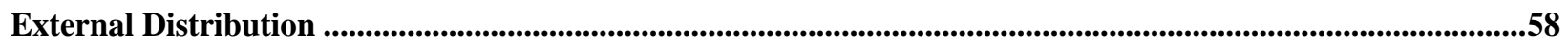




\section{Abstract}

Approximately 68\% of the aluminum produced in the United States is first cast into ingots prior to further processing into sheet, plate, extrusions, or foil. The direct chill (DC) semi-continuous casting process has been the mainstay of the aluminum industry for the production of ingots due largely to its robust nature and relative simplicity. Though the basic process of DC casting is in principle straightforward, the interaction of process parameters with heat extraction, microstructural evolution, and development of solidification stresses is too complex to analyze by intuition or practical experience.

One issue in DC casting is the formation of stress cracks [1-15]. In particular, the move toward larger ingot cross-sections, the use of higher casting speeds, and an ever-increasing array of mold technologies have increased industry efficiencies but have made it more difficult to predict the occurrence of stress crack defects. The Aluminum Industry Technology Roadmap [ recognized the challenges inherent in the DC casting process and the control of stre selected the development of "fundamental information on solidification of alloys to predict microstructure, surface properties, and stresses and strains" as a high-priority research need, and the "lack of understanding of mechanisms of cracking as a function of alloy" and "insufficient understanding of the aluminum solidification process," which is "difficult to model," as technology barriers in aluminum casting processes.

The goal of this Aluminum Industry of the Future ( industry in reducing the incidence of stress cracks $f$ the current level of $5 \%$ to $2 \%$. Decreasing stress crack incidence is important for improving product quality and consistency as well as for saving resources and energy, since considerable amounts of cast metal could be saved by eliminating ingot cracking, by reducing the scalping thickness of the ingot before rolling, and by eliminating butt sawing. Full-scale industrial implementation of the results of the proposed research would lead to energy savings in excess of 6 trillion Btu by the year 2020. The research undertaken in this project aimed to achieve this objective by a collaboration of industry, university, and national laboratory personnel through Secat, Inc., a consortium of aluminum companies. During the four-year project, the industrial partners and the research team met in 16 quarterly meetings to discuss research results and research direction. The industrial partners provided guidance, facilities, and experience to the research team. The research team went to two industrial plants to measure temperature distributions in commercial 60,000-lb DC casting ingot production.

The project focused on the development of a fundamental understanding of ingot cracking and detailed models of thermal conditions, solidification, microstructural evolution, and stress development during the initial transient in DC castings of the aluminum alloys 3004 and 5182. The microstructure of the DC casting ingots was systematically characterized. Carefully designed experiments were carried out at the national laboratory and university facilities as well as at the industrial locations using the industrial production facilities. The advanced computational capabilities of the national laboratories were used for thermodynamic and kinetic simulations of phase transformation, heat transfer and fluid flow, solidification, and stress-strain evolution during DC casting. The achievements of the project are the following: 
- Identified the nature of crack formation during DC casting. Before this project, the industrial consensus was that the cracking of DC casting occurs below the solidus temperature of the alloys. The project results indicate that the cracking is hot tearing which occurs above the nonequilibrium solidus temperature of the alloy.

- Developed a novel method for determining the mechanical properties of an alloy at the nonequilibrium mushy zone of the alloy. Because hot tearing occurs at temperatures at which the alloy contains a small fraction of nonequilibrium liquid among small grains obtained at high cooling rates, existing methods cannot be used for measuring the mechanical properties of an alloy at DC casting conditions. A new method has been developed and used for measuring the data not available in the literature. Using this method, a large number of data have been generated on the mechanical properties of alloy in the nonequilibrium mushy zone.

- Measured heat transfer coefficients (HTCs) between the solidifying ingot and the cooling water jet. A series of temperature measurements was carried out at the industrial production facilities. An inverse calculation method was used to determine the HTCs from the temperature measurement data. HTCs as functions of temperature and water flow rate were estimated.

- Determined the material constitutive model at high temperatures. Carefully controlled experiments were carried out at high temperatures to determine the stress-strain relationship of the alloy. The material property data were obtained and fit into a constitutive model that can be incorporated into a stress-strain model for the simulation of stress-strain evolution in DC casting ingots during solidification.

- Developed computational capabilities for the simulation of cracking formation in DC casting ingot. Models have been developed to simulate heat transfer, fluid flow, phase transition and evolution of the as-cast structure, and stress-strain for the prediction of solidification, microstructure, shrinkage, ingot distortion, and stress-strain during DC casting. The models have validated against the temperature measurement data using the material property data and HTCs obtained in this project. The validated models are ready to be incorporated into commercial software so that they will be accessible to industry and be amendable to refinement in the future. Methodologies of using thermodynamic simulations for the prediction of cracking susceptibility have also been developed. The relationship between the cracking susceptibility and the composition of the alloy has been ascertained.

The models and the database developed in this project have been used to predict crack formation and to determine the optimal conditions for DC casting. The results demonstrated that cracking formation is strongly affected by casting conditions and the composition of the alloy. Scrap rate due to crack formation can be significantly reduced by controlling the cast speed and the concentrations of the alloy.

\section{Statement of Objectives}

To assist the aluminum industry in reducing the incidence of stress cracks to $2 \%$, this project focusing on gaining insights into the mechanisms of stress crack formation during the initial transient in the DC casting of aluminum alloys, developing a computational tool to aid in crack prediction, and optimizing process parameters and ingot geometry. The project included the following activities:

1. Conducting experimental measurements of the extremely non-uniform heat removal at the ingot surface under industrial conditions 
2. Characterizing ingot distortion and the solidification microstructure in detail and developing computer models of the DC casting process for predicting the fluid flow, temperature, and stress fields, and microstructural evolution

3. Determining material properties and developing criteria for crack formation based on a fundamental understanding of the interaction between the solidification microstructure, the local stress, and solidification conditions

4. Demonstrating and validating the models for predicting crack formation, and optimizing process parameters and ingot geometry for a commercial installation

5. Implementing the models developed in the project in a commercial casting code so that the capability will be accessible to industry and amenable to refinement in the future

The proposed research plan was to achieve its objectives by a collaboration among industry, national laboratories [ORNL, Argonne National Laboratory (ANL), and Albany Research Center (ARC)], and University of Kentucky (UK) personnel. The project applied and built on the substantial efforts and capabilities of team members in the understanding of material behavior and processing; the computer modeling of heat flow, fluid flow, and stress; and the characterization of microstructure and mechanical properties. It leveraged the results of the significant effort already under way at ORNL in the modeling of porosity and microstructure in castings.

This investigation was unique because it incorporated all the results from previous studies and, in addition, accounted for the effect of solidification conditions and microstructure, incorporated a realistic criterion for crack prediction, and validated the model for ingots produced under industrial conditions in multiple installations. Finally, the models developed in the project have been implemented in a commercial casting code so that they will be accessible to industry and amenable to refinement in the e.

The objective of this project involved completion of the following tasks:

1. Characterization of heat transfer at ingot surfaces - This task involved the measurement of temperatures in DC ingots and the determination of HTCs in various regions on the ingot surface. The measurements were required to be carried out in industry during the casting of an ingot and involved industry, ORNL, ARC, and UK personnel. An accurate description of the heat transfer from the ingot surfaces is critical for a realistic modeling of the DC casting process.

2. Characterization of the solidification microstructure of ingot - This task focused on characterizing the solidification microstructure as a function of process conditions. This information was extremely useful for developing criteria for crack formation. Industry and ORNL personnel participated in the measurements.

3. Modeling of fluid flow, heat transfer, solidification, microstructure, and stress and strain - Models were used or developed at ORNL to simulate heat transfer, fluid flow, phase change, the evolution of the as-cast microstructure, and stress and strain to enable the prediction of solidification, microstructure, shrinkage, ingot distortion, and cracks during 
DC casting. The models were validated using the results obtained in Task 2. ORNL, UK, and Secat personnel participated in this task.

4. Determination of physical and mechanical properties and criteria for crack formation This task focused on determining the thermophysical and mechanical properties of the material in the solid and mushy regions, carrying out fundamental studies needed for developing the appropriate material constitutive models, and providing insights needed in the formulation of a criterion for crack formation. Criteria for crack formation had to be determined. The results of this task were used as inputs into the models developed in Task 3. ORNL, UK, and ANL personnel participated in this task.

5. DC casting optimization - The fluid flow, heat transfer, solidification, microstructure, and stress models were used to optimize cooling conditions, casting parameters, and ingot geometry in order to allow for improved process control and product quality in production ingots. ORNL and industry personnel collaborated on this task. In order to allow the models developed in the project to be used by industry, the ORNL and UK personnel worked with a commercial software vendor to implement the DC casting model into a commercial code.

6. Final report - A comprehensive report on all phases of the project was to be produced. The report was required to contain detailed instructions on the use and application of the DC casting model.

\section{Benefits to the Funding DOE Office's Mission}

The energy and cost savings and the environmental impact of this project are significant. The U.S. aluminum industry produces 20 billion lb of aluminum annually [1]. Assuming that the melt loss of aluminum is $4 \%$, a scrap rate reduction from $5 \%$ to $2 \%$ could lead to an energy saving of 7 trillion Btu, and a cost saving of \$37 million by the year 2025. These energy and cost savings were estimated using the Industrial Technologies Program (ITP) spreadsheet under assumptions that annual growth of aluminum production is $2 \%$ and that the market share of the project results is $100 \%$.

\section{Technical Discussion of Work Performed by All Parties}

\subsection{Heat Transfer at Ingot Surfaces}

\subsubsection{Introduction}

The DC casting process has been the mainstay of the aluminum industry for the production of billets and ingots since the late 1930s, largely because of its robustness and relative simplicity. Unfortunately, the process can produce distortions in the ingot, and cracks can form owing to the non-uniform, high rate of heat removal imparted by the direct contact of the bottom block or water with the partially solidified ingot. An accurate estimation of heat transfer coefficients 
(HTCs) at the ingot surface is essential in the prediction of ingot cracking during DC casting of aluminum alloys.

In general, the ingot surface experiences three different heat transfer regimes: direct contact with the mold, the air gap region, and the water cooling region, as shown in Fig. 4.1.1. The water cooling region is usually divided into three modes - convection, nucleate boiling, and film boiling - depending on the temperature of the ingot surface [16]. In the film boiling mode, the surface is covered with vapor film, and liquid does not contact the solid, whereas nucleate boiling is a very efficient mode of heat transfer because of the latent heat of water. In such cases, the HTC in the water cooling region is a function of temperature and water flow rate. Furthermore, it also depends on parameters such as ingot size and geometry, the casting alloy, and casting speed. Therefore, the HTCs need to be estimated for each case.

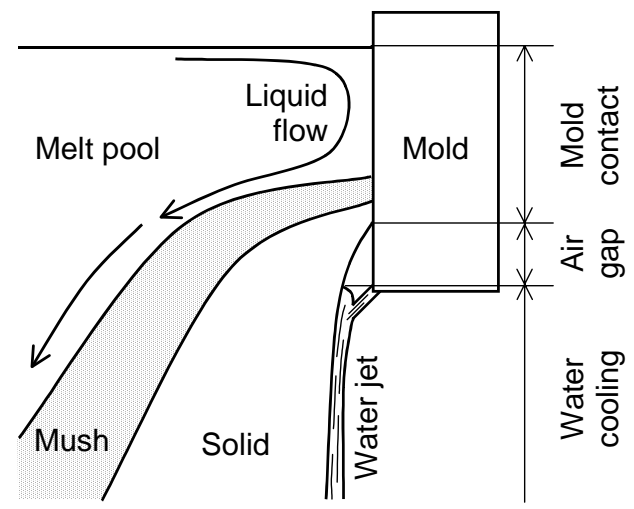

Fig. 4.1.1. The three different heat transfer regimes commonly encountered in the DC casting process.

A number of factors affect the heat transfer rate at the ingot surface in the water cooling region other than the process parameters mentioned above. These include the change in the water temperature along the surface and water quality (via change in water's thermophysical properties and/or boiling point elevation). Therefore, theoretical prediction of the HTC is possible in principle but not practical. This section presents the effort of the research team to determine the apparent HTC using transient two-dimensional (2D) inverse analysis. Temperature distributions in the DC casting ingot were measured at Wagstaff, Inc., and Aleris International. Figure 4.1.2 shows a photo of temperature measurement at Aleris International's Newport plant. Based on the measured temperatures, inverse analyses were carried out to determine the apparent HTCs as a function of the surface temperature and time. 


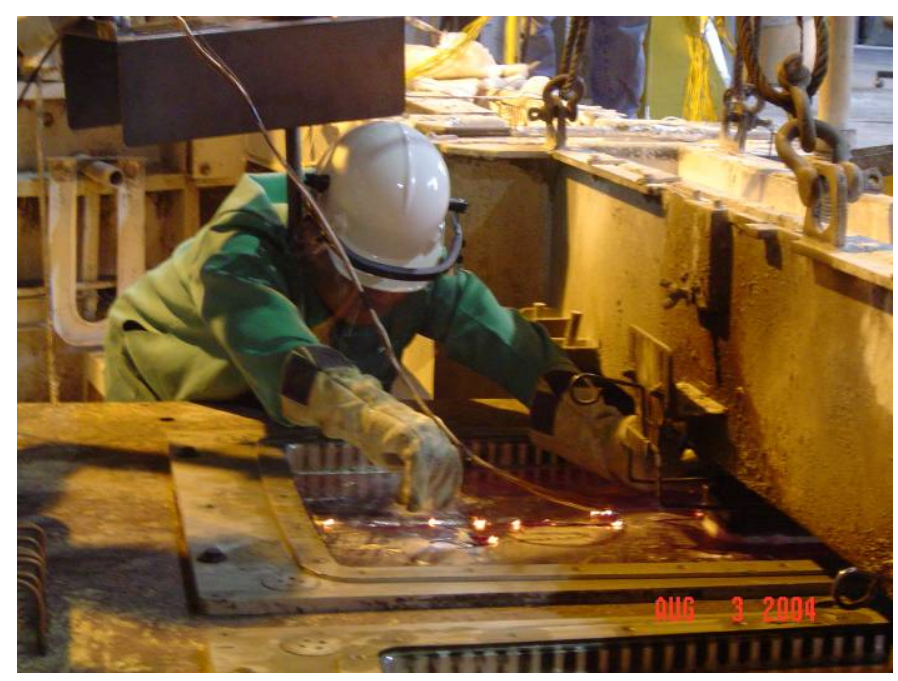

Fig. 4.1.2. A researcher placing a temperature jig into the molten aluminum in a DC casting mold at Aleris International's Newport plant.

\subsubsection{Temperature Measurement}

The objective of the experiments was to collect temperature data in industrial-sized DC cast ingots during casting and solidification. A combination of the methodologies of Chang and Kang [17] and Drezet et al. [18] was employed. Type $\mathrm{K}$ thermocouples were selected as the probe material to be inserted into the ingots while they were solidifying. The thermocouples were fastened to jigs constructed from steel rods approximately $3 \mathrm{~mm}$ in diameter. The rods were welded into L-shaped rigid fixtures with stiffening members such that the assembly could be handled and placed into position without significant deflection. The thermocouples themselves were heavy gauge, to avoid being dissolved in the molten aluminum, and were covered with an insulating fiber sheath.

Thermocouple data were successfully collected for the mold, starting block, ingot surface, and ingot interior. Data were recorded at $20 \mathrm{~Hz}$ using a data acquisition system during a standard casting of aluminum 3004 alloy. In order to completely characterize ingot temperatures, two types of measurements were conducted. The first jig contained thermocouples placed at locations close to the ingot surface, while a second jig contained thermocouples designed to measure temperatures in the ingot interior. For both the surface profile and the interior profile, multiple jigs with thermocouples attached were inserted in layers. During casting, each jig was inserted into the liquid metal at a predetermined ingot position. After the jig was trapped in place by the solidifying metal, it moved downward at the casting speed of the ingot. The interval between insertions was more frequent at the start of the casting and became less frequent as the casting process approached steady state, because ingot cracking usually occurs in the initial transient period of the casting process. Useful information was collected for 12 of the 15 jigs prepared.

Figure 4.1.3 shows schematic diagrams of thermocouple locations for surface and interior temperature measurements. Each surface location [Fig. 4.1.3(a)] contained an assembly of three thermocouples placed $2.5 \mathrm{~mm}$ apart to allow extraction of the heat flux at the surface. A fourth thermocouple was added at locations A and D approximately $7 \mathrm{~mm}$ from the last thermocouple. Interior thermocouples were of two types. As shown in Fig. 4.1.3(b), locations A and D 
contained an assembly of four thermocouples, while locations B and C contained an assembly of two thermocouples. Locations further interior in the ingot were single thermocouples. Figure 4.1.4 shows pictures of the thermocouple assembly and jig used for surface temperature measurements.

A series of infrared (IR) thermographs was taken during casting to obtain 2D temperature maps of the ingot surface. Figure 4.1.5 shows an IR image of the ingot surface just below the mold. The image was taken at the start of the cast. The bottom part of the image shows the bottom block as indicated in the figure. The temperature of the bottom block is lower than $100^{\circ} \mathrm{C}$, a temperature

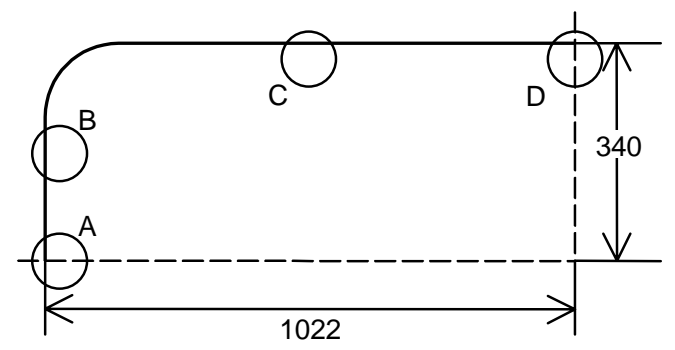

A \& D: 4 thermocouples @ 1, 3.5, 6, $13 \mathrm{~mm}$ from the surface B \& C: 3 thermocouples @ 1, 3.5, $6 \mathrm{~mm}$ from the surface

(a)

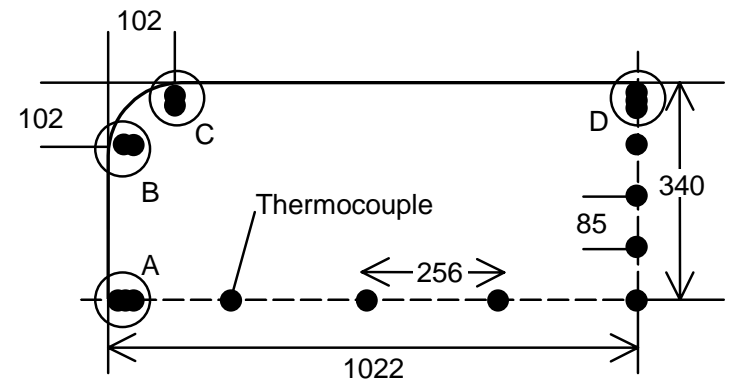

A \& D: 4 thermocouples @ 13, 25, 38, $51 \mathrm{~mm}$ from the surface B \& C: 2 thermocouples @ 22, $35 \mathrm{~mm}$ from the surface

(b)

Fig. 4.1.3. Thermocouple locations $(\mathrm{mm})$ for $(a)$ surface and $(b)$ interior temperature measurements.

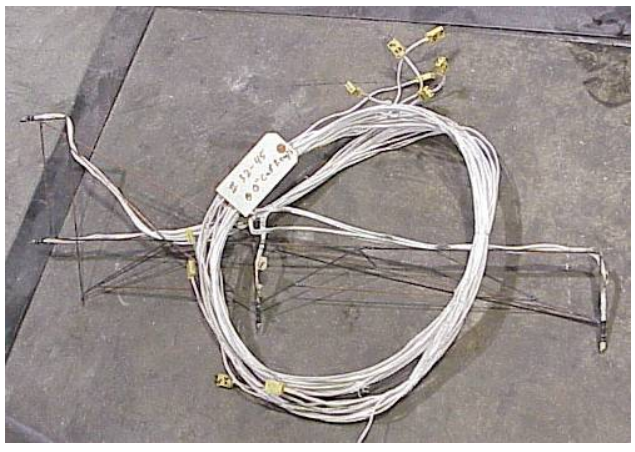

(a)

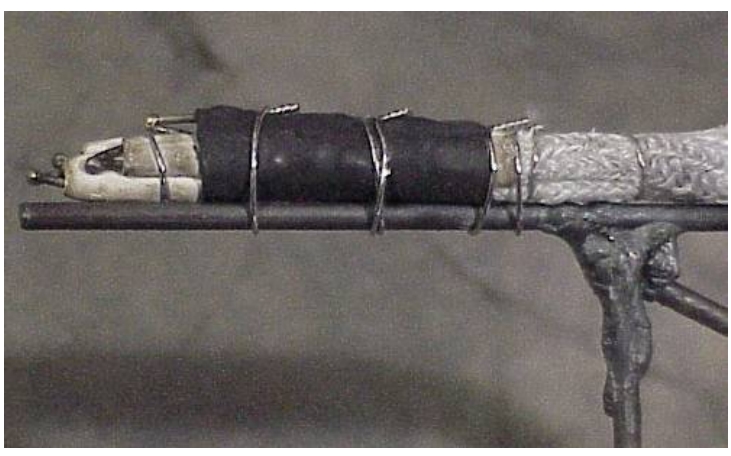

(b) 
Fig. 4.1.4. Thermocouples for surface temperature measurement, showing (a) thermocouple assembly and (b) closeup of thermocouple tips attached to jig.

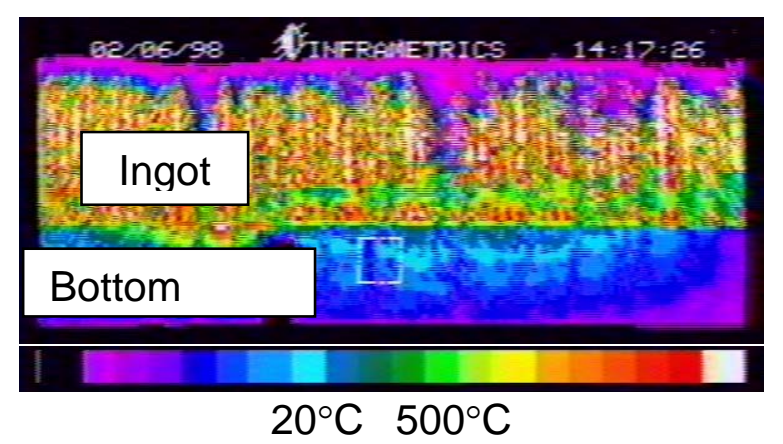

Fig. 4.1.5. Two-dimensional temperature map of the ingot surface obtained by an IR camera.

much lower than that of the ingot surface. The ingot surface temperature is about $500^{\circ} \mathrm{C}$, suggesting the heat transfer there is in the film boiling mode. It can be seen that the isothermal lines are nearly horizontal, indicating that 2D simulation is applicable to this case.

\subsubsection{The Inverse Model for HTCs}

Since inverse heat transfer analysis requires multiple computational iterations, it is highly timeconsuming. Accordingly, a 2D calculation was conducted. The computational domain used for the simulation is shown in Fig. 4.1.6.

The model included heat transfer, phase change, and fluid flow. A standard set of conservation equations was solved using the commercial casting simulation package $A$ AST. In the formulation, a source term containing the Darcy equation and the perme momentum equation to simulate the effect of flow in mushy regions and to drive the velocities to zero when the metal is fully solid. The inverse modeling module of ProCAST can determine 
Fig. 4.1.6. Two-dimensional computational domain used for this study.

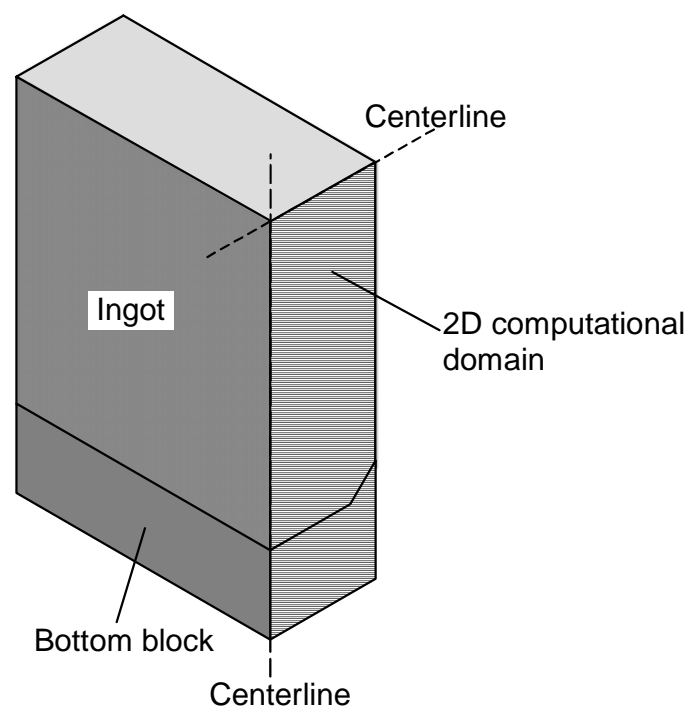

boundary conditions from temperature measurements [19]. It uses the thermal history generated by ProCAST as an input for deriving boundary conditions. Figure 4.1.7 shows the flow chart of the inverse calculation. The first step of the calculation is to assume reasonable HTCs at the ingot surface. The temperature profile of the ingot is then calculated using the assumed HTCs, and the calculated temperatures are compared with the corresponding thermocouple data. The inverse module of ProCAST modifies the HTCs based on the difference between the calculated and measured temperatures. This process is repeated until the errors between the calculated and measured temperatures are reasonably small. A typical run took about 100 min of CPU time; 135 runs were needed to obtain converged HTCs. The total CPU time was about 10 days.

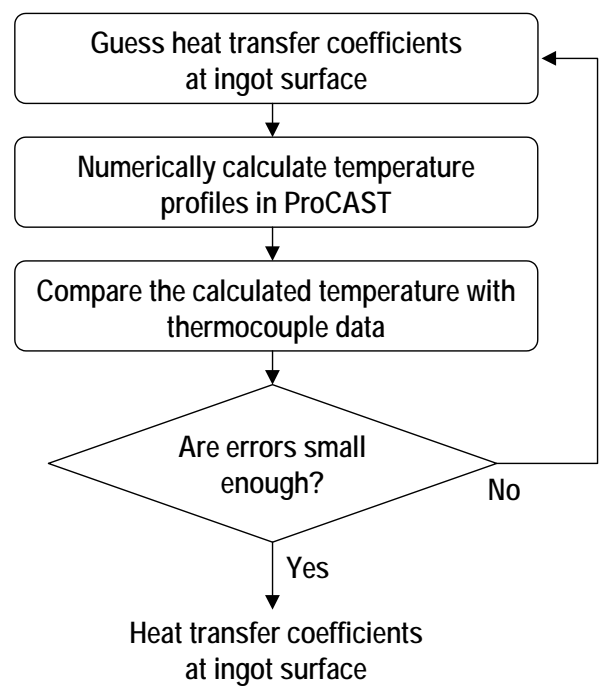

Fig. 4.1.7. Flow chart of inverse calculation. 
Constant values were assigned to the HTCs in both the mold contact region and the air gap region (2000 and $200 \mathrm{~W} / \mathrm{m}^{2} \mathrm{~K}$, respectively). The effect of the water flow rate, $W(225 \mathrm{~L} / \mathrm{min}$ at the beginning of the cast and $760 \mathrm{~L} / \mathrm{min}$ at the end of the cast), on the HTC was taken into account as shown in Eq. (4.1.

$$
h(T, W(t))=0.5\left(1+\frac{W(t)}{W_{0}}\right) h_{0}(T),
$$

where $h_{0}$ is the HTC at the water flow rate of $W_{0}$. The water temperature was assumed to be constant (i.e., room temperature). All process parameters (casting speed, water flow rate, etc.) used in the simulation were the same as those of the experimental casting run for which thermocouple data was obtained.

The first attempt used an unstructured mesh for the computation. A fine mesh was used at the locations of the surface thermocouples because the temperature at those locations is required for inverse analysis. As a consequence, the mesh size varied significantly in the vicinity of the surface thermocouples. Therefore, the predicted solidification pattern showed a significant error after the top surface of the ingot passed the locations of the surface thermocouples. The predicted fraction solid indicated that the temperature at the top surface was lower than that below the surface, which was not realistic. Therefore, a structured mesh was generated with a finer mesh in the region close to the ingot surface. The fine mesh was generated not only at the thermocouple locations but also along the ingot surface; this step improved the accuracy of the computation because a large temperature gradient is present close to the ingot surface due to water cooling.

\subsubsection{Results and Discussion}

Figure 4.1.8 shows measured and computed temperature histories at two representative locations in the ingot: $1 \mathrm{~mm}$ and $12.7 \mathrm{~mm}$ from the ingot surface. Computed and measured temperatures show reasonable agreement, suggesting that the calculated apparent HTC is reasonable. There is a larger difference between the measured and computed temperatures at $12.7 \mathrm{~mm}$ from the ingot surface, as the inverse calculation was based primarily on thermocouple data close to the surface. However, no significant error was observed at all the locations examined.

Figure 4.1.9 shows the apparent HTC in the water cooling region obtained by inverse analysis. The HTC at water flow rates between its minimum and maximum was linearly interpolated as indicated by Eq. (1). The calculated HTCs are typical of those for water cooling. The peak in the data is associated with the high rates of heat transfer during nucleate boiling. The profile is consistent with data published in the literature [18]. 


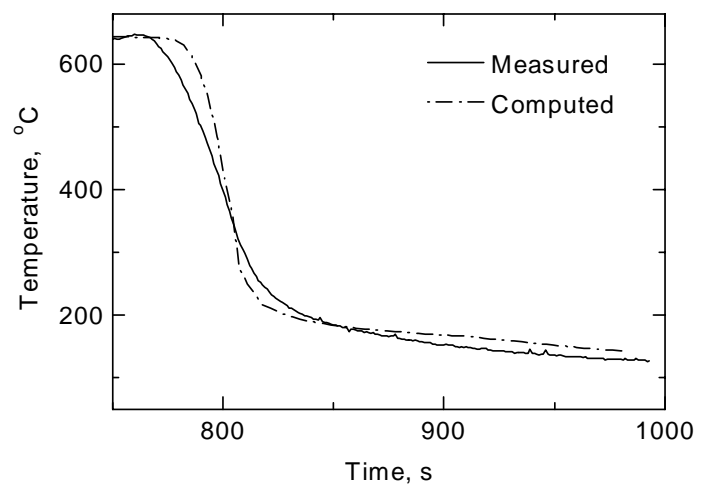

(a)

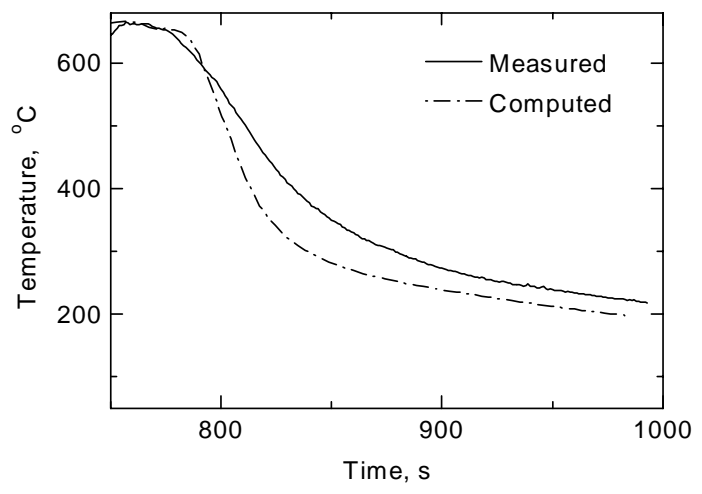

(b)

Fig. 4.1.8. Comparison between measured and computed temperatures: (a) $1 \mathrm{~mm}$ from ingot surface; (b) $12.7 \mathrm{~mm}$ from ingot surface.

Fig. 4.1.9. Calculated apparent HTC in the water cooling region at minimum $(225 \mathrm{~L} / \mathrm{min})$ and maximum (760 L/min) water flow rates.

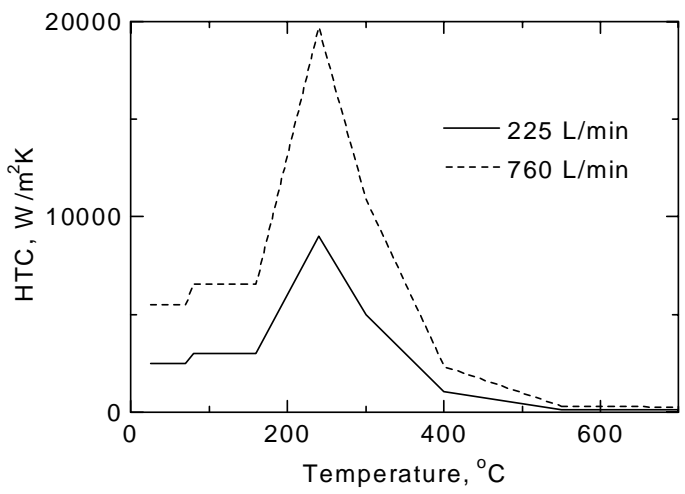

In summary, the apparent HTC at the ingot surface in the water-cooling region during DC casting was determined on the basis of inverse heat transfer analysis. A transient, 2D model with fluid flow, heat transfer, and solidification was used for the inverse analysis. A structured computational mesh with finer mesh in the region close to the ingot surface was generated to accurately simulate the heat transfer through the surface. Input to the analysis included temperatures at locations near the ingot surface and the center obtained from experimental measurements on an industrial-scale ingot.

The HTCs were calculated as a function of temperature and time and covered the different regimes of heat transfer expected during DC casting. The calculated values were extrapolated to include the effect of water flow rate.

The calculated HTCs had a peak at around $200^{\circ} \mathrm{C}$, corresponding to the high heat transfer rates during nucleate boiling, and the profile was consistent with similar data published in the literature. The computed temperatures showed good agreement with measured temperatures, validating the model, and provide further confirmation that the computed HTCs were reasonable. The distributions of temperature and fraction solid in the ingot before and after the initiation of nucleate boiling showed significant differences due to the difference in the HTC between nucleate and film boiling modes. 


\subsection{Nature and Formation of Surface Cracks in DC Cast Ingots}

\subsubsection{Introduction}

Surface cracks are one type of crack that increases the cost and reduces the yield of the DC casting process. Figure 4.2.1 shows one quarter of a horizontal cross section of an aluminum alloy 3004 ingot with overall dimensions of $28 \times 73 \times 300$ alloy 3004 is given in Table 4.2.1. The section shown in $\mathrm{Fi}_{\circ}$. .1 was obtained approximately 6 in. from the bottom of the ingot. Small surface cracks (marked $A$ and $B$ in the figure) occur near the middle and quarter point of the rolling surface of the ingot. Most of the surface cracks form during the start-up phase of ingot casting, usually at a distance approximately 6 in. from the bottom of the ingot.

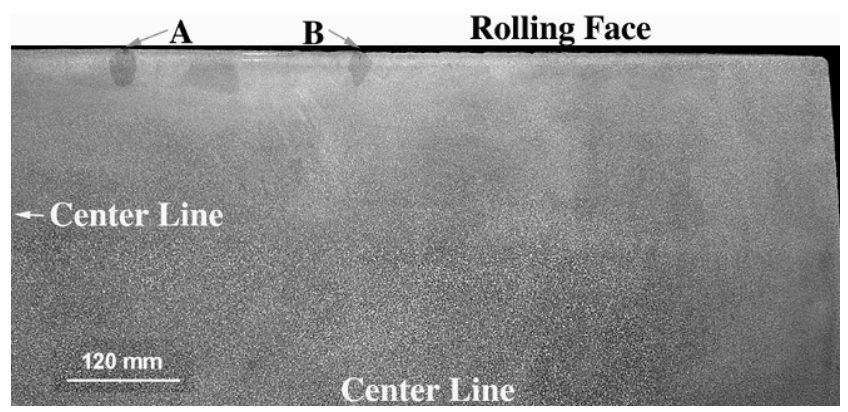

Fig. 4.2.1. One quarter of a horizontal cross section of a DC cast aluminum 3004 ingot. Surface crack locations are indicated by $A$ and $B$.

\begin{tabular}{cc}
$\begin{array}{l}\text { Table 4.2.1. Nominal } \\
\text { composition of } \mathbf{3 0 0 4} \text { alloy }\end{array}$ \\
\hline $\mathrm{Mg}$ & $\mathbf{W t} \%$ \\
\hline $\mathrm{Fe}$ & 1.25 \\
$\mathrm{Si}$ & 1.0 \\
$\mathrm{Zn}$ & 0.7 \\
$\mathrm{Cu}$ & 0.3 \\
$\mathrm{Al}$ & 0.25 \\
& 0.2 \\
\end{tabular}

Research has been carried out to control the formation of surface cracks [7, 9-11], but the nature of the crack formation is unclear. During DC casting, the ingot surface is in direct contact with either a metal mold or cooling water. This often leads to expectations that the surface crack could be a cold crack, i.e., one that occurs below the solidus temperature of the alloy, rather than a hot tear, i.e., one that occurs above the solidus temperature. It is difficult to believe that the stresses and strains generated during DC casting due to the uneven shrinkage of the ingot can produce cracks in solid aluminum that is highly ductile at elevated temperatures. The purpose of this study was to clarify the nature of the surface cracking-i.e., whether it is a cold crack or a hot tear. This is very important for the simulation and prediction of surface cracking, as the criteria for the formation of hot tear and cold crack are markedly different.

\subsubsection{Experimental Results}

Cracked samples were taken directly from the surface of the DC cast 3004 aluminum alloy ingot shown in Fig. 4.2.1. The microstructure around the crack was examined using an optical microscope. The samples were then fractured along the crack. The fracture surface was examined using scanning electron microscopy (SEM) and Auger electron spectroscopy (AES). The middle photograph in Fig. 4.2.2 shows the entire crack. The top micrograph in Fig. 4.2.2 shows the crack and the microstructure near the surface of the ingot. The bottom micrograph in 
the figure shows the tip of the crack and the microstructure near the tip. The grains are equiaxed throughout the ingot due to the addition of a grain refiner. If we track the crack from the ingot surface all the way to its tip, we see that the crack is formed along dendrites and grain boundaries. No transgranular cracking is observed. At the tip of the crack, small secondary cracks invisible to the naked eye are evident. These secondary cracks are discontinuous but are also formed along dendrites and grain boundaries.

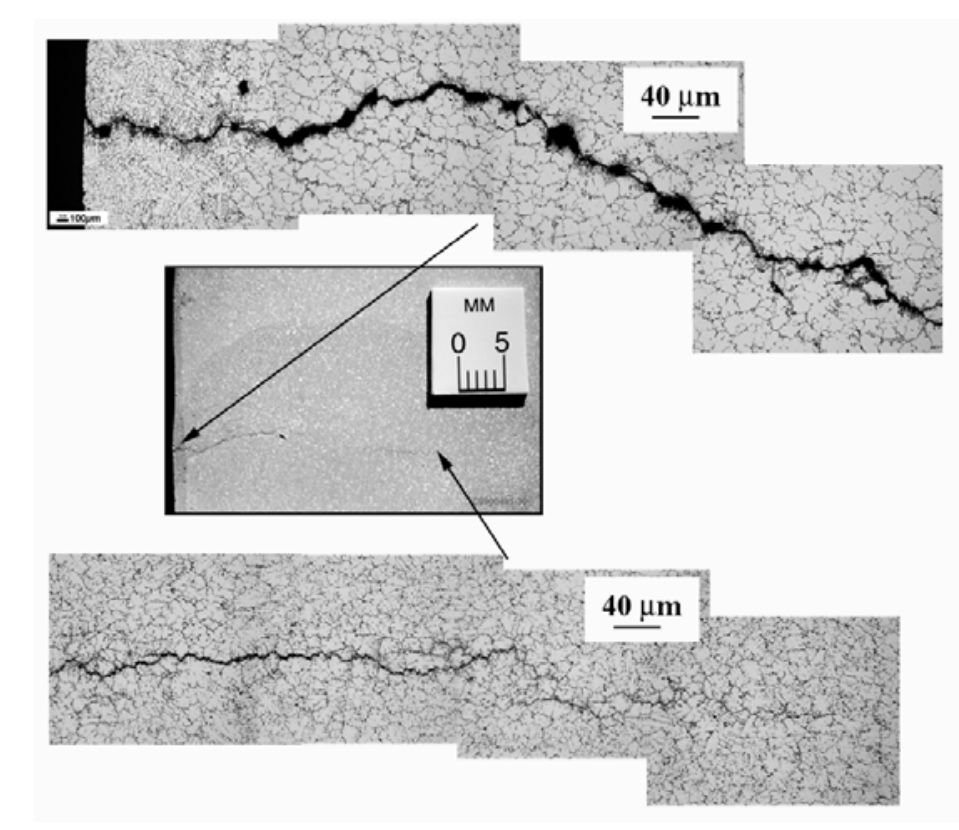

Fig. 4.2.2. A surface crack, shown in the middle of the figure, with enlarged views at the top and bottom indicating the surrounding microstructure. Note that the crack lies between dendrites or along grain boundaries.

If we fracture the sample along the crack, we can observe the morphology of the crack surface using SEM. As shown in Fig. 4.2.3, dendrites are clearly visible on the fracture surface. This is evidence that the crack is due to hot tearing. If the fracture had occurred at temperatures below the solidus temperature of the alloy, the fracture would probably be transgranular. The dendritic morphology of the fracture surface is usually an indication that the fracture occurred near the end of solidification when some liquid was present in the interdendritic region, but was not enough to fill or heal the crack. 


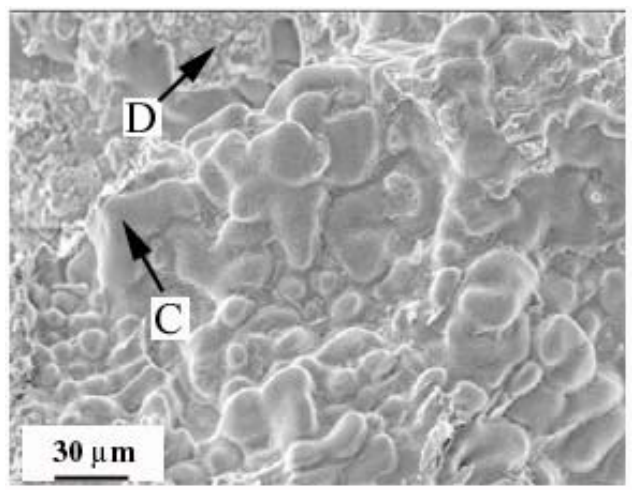

Fig. 4.2.3. Scanning electron microscopy image of a crack surface. Dendrites are clearly visible on the fracture surface. $C$ indicates a point on a primary aluminum dendrite, while $D$ indicates the eutectic region.

In order to reveal the mechanism of crack formation, AES was used to determine concentration depth profiles, i.e., the concentration of elements in the solid as a function of distance beneath the surface. Two locations on the fracture surface $-C$ on a dendrite surface and $D$ in the eutectic region (shown in Fig. 4.2.3) - were chosen for analysis. Figures 4.2.4(a) and (b) show the concentration depth profiles for regions $C$ and $D$, respectively. At the fracture surface, a high carbon concentration was detected, indicating atmospheric contamination. This was expected, as a significant amount of time elapsed between the casting of the ingot and the analysis. When a layer approximately $0.5 \mu \mathrm{m}$ thick was removed by sputtering, high concentrations of oxygen and aluminum ware detected, indicating the presence of $\mathrm{Al}_{2} \mathrm{O}_{3}$. It is likely that the oxide formed before the crack surface was contaminated and represents the position of the fracture surface. Further analysis of successive depths below the fracture surface indicated the segregation of magnesium in both locations $C$ and $D$. In location $C$, the magnesium concentration decreased rapidly with depth, consistent with what would be expected at the surface of a primary aluminum dendrite. In location $D$, the magnesium concentration was uniform over a depth of a few microns, consistent with what would be expected in the eutectic region. These results further confirm that the fracture surface corresponds to a fracture path along the interdendritic regions, rather than through the grains.

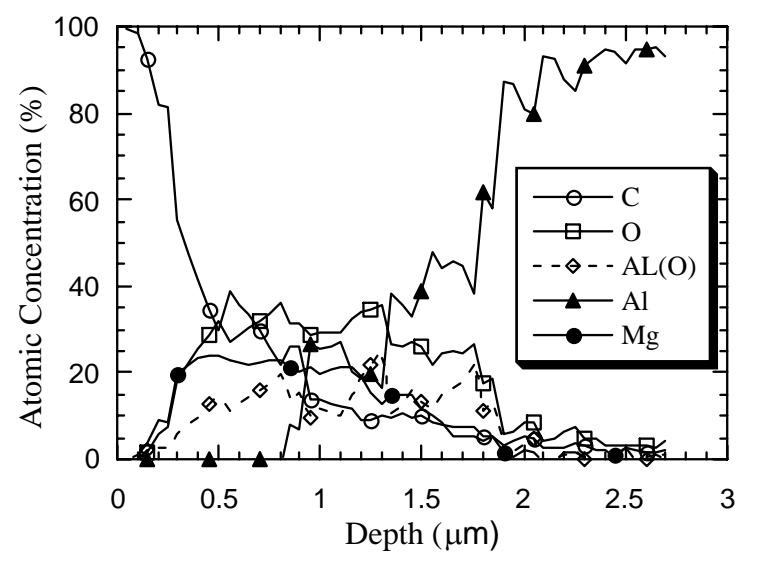

(a) 


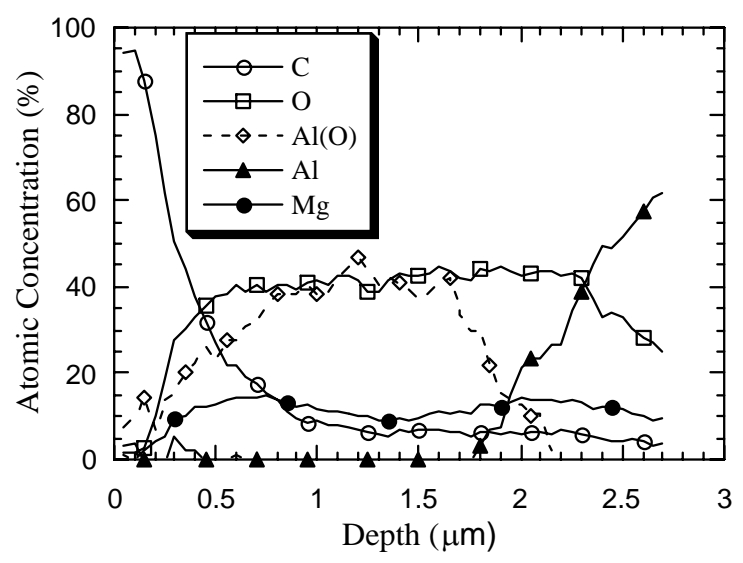

(b)

Fig. 4.2.4. Composition depth profiles into the fracture surface (a) at a primary aluminum dendrite and (b) in the eutectic region.

The area elemental distributions, determined using AES, are shown in Fig. 4.2.5. The area chosen for measuring elemental distributions, shown in Fig. 4.2.5(a), was chosen such that the right-hand side contained dendrites and the left-hand side contained the eutectic phases in which intermetallics can be seen. A layer of material approximately $1 \mu \mathrm{m}$ thick was sputtered off before the elemental distributions were obtained. Figures 4.2.5(b), (c), and (d) show the elemental distributions of magnesium, silicon, and iron, respectively. Magnesium segregates to the interdendritic region and at the surface of primary aluminum dendrites. Silicon and iron also segregate to the interdendritic region and, in addition, form intermetallic phases. Iron, in particular, has low solubility in aluminum and is found only in the interdendritic regions as intermetallic phases. Figures 4.2.5(c) and (d), in particular, confirm the presence of intermetallic phases containing silicon and iron on the fracture surface, providing strong confirmation that the likely fracture path is along the interdendritic region.

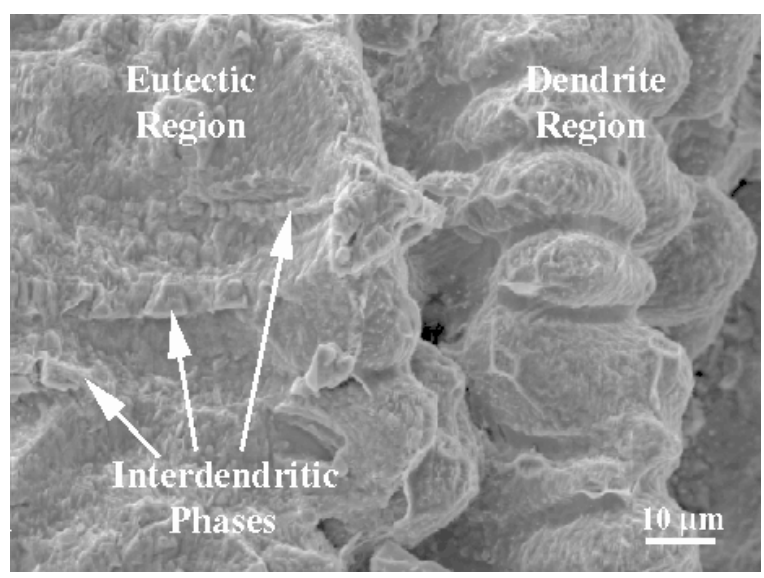

(a)

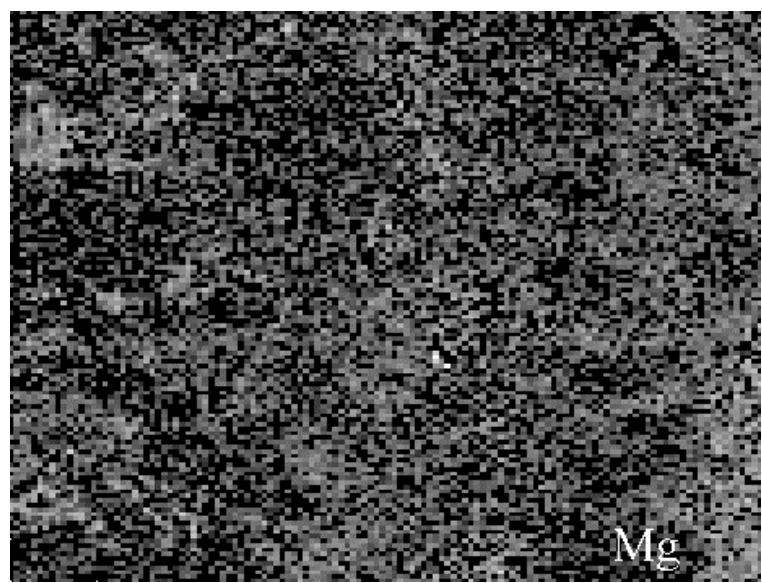

(b) 


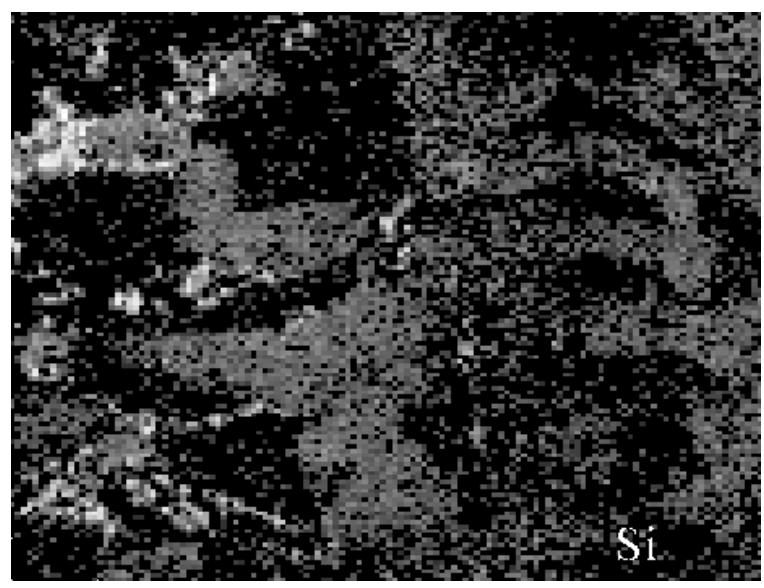

(c)

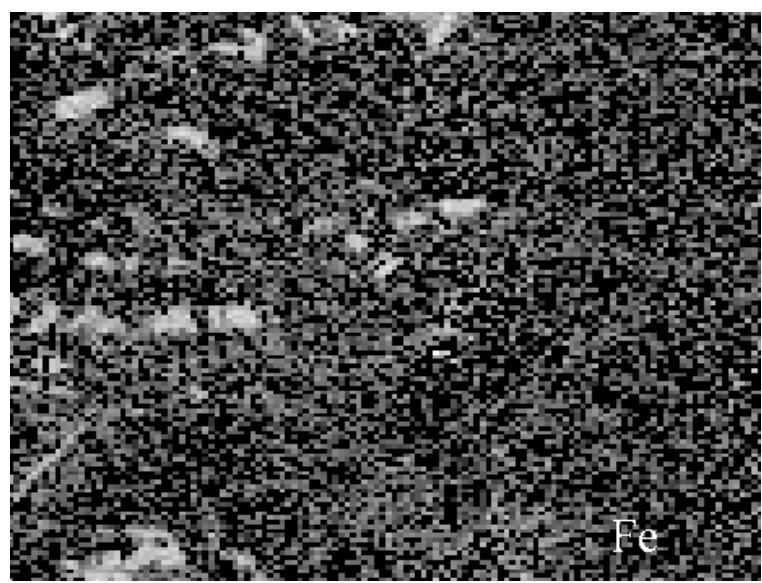

(d)

Fig. 4.2.5. SEM (a) and AES (b,c,d) microanalysis in a selected area on the fracture surface showing (a) a micrograph of the selected area, (b) magnesium elemental distribution, (c) silicon distribution, and (d) iron elemental distribution.

In summary, Figs. 4.2.2 and 4.2.3 provide visual indications that the fracture path is along the interdendritic region. Figures 4.2.4 and 4.2.5 provide evidence of significant elemental segregation and the presence of intermetallic phases on the fracture surface, confirming that the fracture surface follows a path along the interdendritic region. This suggests that the crack is a hot tear. Prior to this work, industry had believed that cracking was "cold cracking" that occurred below the nonequilibrium solidus temperature of the alloy.

\subsubsection{Solidification Analysis}

Another question that needs to be addressed is at what temperatures the crack might occur if the surface cracking is hot $\mathrm{lg}$. The equilibrium solidus temperature of the 3004 alloy is $624^{\circ} \mathrm{C}$. The surface temperatur ${ }_{-}$the DC ingot seldom reach such high temperatures. However, solidification is a nonequilibrium process, and segregation also occurs during solidification. The segregation of elements to the interdendritic regions will reduce the local solidus temperature, and the solidus temperatures in these highly segregated regions will be much lower than the equilibrium solidus temperature of the alloy.

Thermodynamic simulations were carried out to determine the solute segregation behavior and its effect on the solidus temperature of the alloy. Figure 4.2.6 shows the segregation of solute elements during the solidification of aluminum alloy 3004 calculated using the thermodynamic simulation software ThermoCalc [20] and a commercially available aluminum database [21]. The segregation was calculated assuming nonequilibrium Scheil conditions commonly prevalent during solidification (i.e., no diffusion of solute in the solid, complete mixing of solute in the liquid, and local equilibrium at the solid-liquid interface). In the literature, the Scheil condition has been widely shown to be appropriate for modeling the solidification of aluminum alloys. 


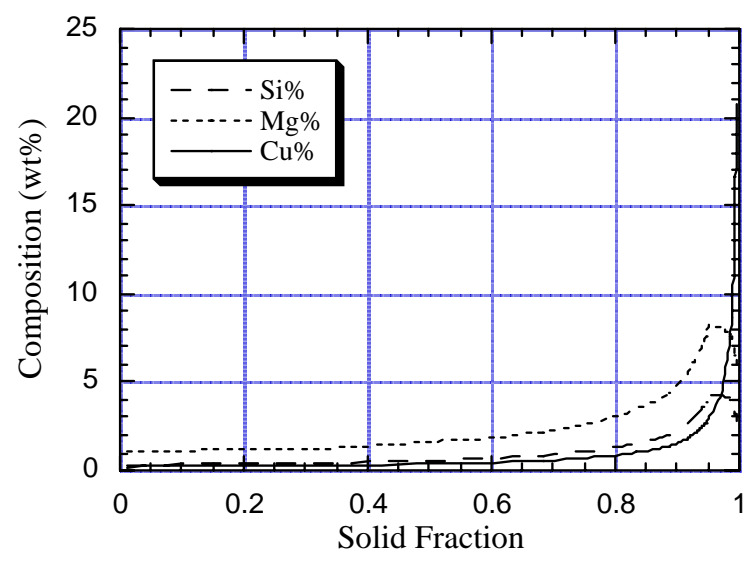

Fig. 4.2.6. Calculated concentrations of solute elements in the interdendritic liquid during solidification of aluminum alloy 3004. Copper, silicon, and magnesium segregate in the last liquid to solidify.

As shown in Fig. 4.2.6, magnesium, silicon, and copper tend to segregate in the last regions to solidify. The concentration of magnesium in the liquid increases from $1 \mathrm{wt} \%$ to about $8 \mathrm{wt} \%$ when the solid fraction reaches 0.9 . The silicon concentration increases from $0.3 \mathrm{wt} \%$ to more than $4 \mathrm{wt} \%$ in the last region to freeze. The copper concentration increases from $0.2 \mathrm{wt} \%$ to more than $20 \mathrm{wt} \%$ until $\mathrm{Al}_{7} \mathrm{Cu}_{2} \mathrm{Fe}$ forms. The segregation of copper, silicon, and magnesium significantly decreases the solidus temperature in the last region to solidify. These regions are usually dendrite or grain boundaries where hot tearing is expected to occur. As shown in Figs. 4.2.2 and 4.2.3, the surface crack occurs along dendrite or grain boundaries. In addition, the comparison of the composition profiles in Fig. 4.2.6 with those in Fig. 4.2.4 indicates that the high levels of magnesium measured on the crack surface are consistent only with a fracture path through the interdendritic region.

Figure 4.2.7 shows plots of the fraction solid vs temperature for aluminum alloy 3004. The top curve was calculated assuming equilibrium conditions (i.e., the lever rule), while the bottom curve was calculated assuming nonequilibrium Scheil conditions. A comparison of the two curves in the figure indicates a significant difference in the calculated solidus temperature for equilibrium and the normal nonequilibrium Scheil-type solidification of aluminum alloy 3004. Whereas the equilibrium phase diagram would predict a solidus temperature of $624^{\circ} \mathrm{C}$, the actual solidus temperatures in the interdendritic regions are significantly lower. In fact, they could be as low as $450^{\circ} \mathrm{C}$, the eutectic temperature of binary aluminum-magnesium alloys. 


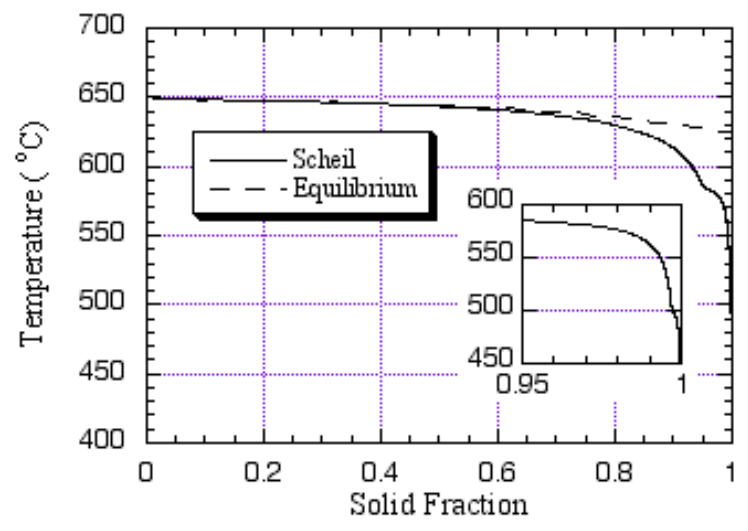

Fig. 4.2.7. Relationship between temperature and solid mole fraction calculated for the solidification of aluminum alloy 3004 . The solidus temperature for nonequilibrium solidification (Scheil type) is much lower than that for equilibrium conditions.

\subsubsection{Discussion}

The surface temperatures of the ingot can be as high as $600^{\circ} \mathrm{C}$ before it reaches the water spray impingement point [22]. This makes it possible for hot tearing to occur because the nonequilibrium solidus temperature of the 3004 alloy can be as low as $450^{\circ} \mathrm{C}$. Surface cracks usually occur within a distance approximately 6 in. from the bottom of the ingot, which is very close to the location where the secondary cooling water jets first contact the surface of the ingot. If tensile stresses are generated at the ingot surface, surface cracks should be able to form. Tensile stresses are likely to exist at the ingot surface in the start-up phase of the ingot, since heat transfer is highly non-uniform near the bottom of the ingot.

The metallographic evidence of the crack pattern, the SEM image of the fracture surface, and an analysis of the solidification behavior of aluminum alloy 3004 all point to the fact that surface cracking is a type of hot tearing. The experimental evidence permits us to establish a phenomenological model of surface cracks in DC cast ingots:

1. Segregation during solidification significantly lowers the solidus temperature of the alloy.

2. The lowered solidus temperature permits interdendritic liquid to persist for longer times during casting, in particular when the solid fraction is close to

3. These conditions make it more likely that interdendritic liquid $\stackrel{=}{=}$ e present when the surface of the ingot experiences tensile stress.

4. The presence of interdendritic liquid embrittles the alloy and promotes hot rearing.

The above analysis suggests that the surface cracks that occur during DC casting of aluminum alloys are hot tears that form above the solidus temperature, rather than cold cracks that form below the solidus temperature. Consequently, the prediction of surface cracking during DC ingot casting requires an analysis of the stress state during casting as well as an analysis of the local solidification conditions - in particular, the effect of microstructure, segregation, and interdendritic liquid. 
In summary, surface cracks that form on the surface of a DC cast ingot within a distance approximately 6 in. from the bottom of the ingot are hot tears. They occur at a location just above the impingement point of the secondary cooling water jets. The cracks form along dendrite and grain boundaries, where solute and impurity elements are highly segregated. Segregation during solidification significantly lowers the solidus temperature of the alloy. In fact, the temperature could be as low as $450^{\circ} \mathrm{C}$, much lower than the equilibrium solidus temperature of the alloy $\left(624^{\circ} \mathrm{C}\right)$. The existence of a liquid film between dendrites embrittles the alloy. Under these conditions, if tensile stresses are generated at the ingot surface due to the highly nonuniform heat transfer during the initial transient in DC casting, surface cracks are formed.

\subsection{Mechanical Properties in the Nonequilibrium Mushy Zone of Alloys}

\subsubsection{Introduction}

Hot tears are defects that form during the solidification of castings. The formation of hot tears is closely related to the mechanical properties of the alloy at small liquid fractions in the mushy zone [23-31]. The common approaches for measuring the mechanical properties of alloys at mushy zone temperatures include the heating method [24-26] and the solidification method [2731]. The most widely used method is the heating method, which involves heating a specimen to the desired mushy zone temperature, holding the specimen at the test temperature for a certain amount of time to obtain a uniform temperature distribution in the gauge length of the specimen, and then measuring the properties. The method is straightforward and relatively easy to use. A fair amount of useful data has been generated using this method. However, there are significant limitations to the accuracy of these methods.

The heating method is fairly accurate when the mushy zone is in equilibrium, but has limitations when the mushy zone is in nonequilibrium and the liquid fraction in the mushy zone is small. Usually, the mushy zone in an alloy is in nonequilibrium during solidification, and hot tearing occurs at small liquid fractions $(<0.1)$ [30]. Duncan, Han, and Viswanathan [32] demonstrated that the liquid fraction decreases rapidly when a specimen is held at mushy zone temperatures due to back diffusion in the solid. During the heating and holding stages of the heating method, the liquid fraction in the specimen decreases with time. The liquid may completely disappear if the liquid fraction is small and the heating/holding time is long. As a result, it is inadvisable to use the heating method to measure the mechanical properties of alloys in the mushy zone at temperatures below the equilibrium solidus temperature of the alloy.

The solidification method involves cooling a specimen from liquid to solid in a mold and measuring the mechanical properties of the alloy during cooling [27-31]. It can be used for measuring mechanical properties in the nonequilibrium mushy zone, but its accuracy is influenced by interactions between the specimen and the mold and by the non-uniform temperature distribution in the specimen. In order to increase the accuracy of the method, the specimen must be solidified slowly in the mold, resulting in the formation of large grains. Because hot tearing is sensitive to grain size, the solidification method has limitations in its application to casting processes in which the cooling rates are high and the grains sizes are small. 
A method was developed in this project that was used for determining the mechanical properties of alloys in the nonequilibrium mushy zone at small liquid fractions.

\subsubsection{Experimental Technique}

\subsubsection{Approach}

The new approach developed in this project for determining the mechanical properties of alloys at nonequilibrium mushy zone temperatures is shown schematically in Fig. 4.3.1. The liquidus temperature, $T_{L}$, and solidus temperature, $T_{S}$, are indicated by dashed lines. The heating and cooling methods are indicated by solid lines and arrows. The new method, termed the reheatingcooling method (RCM), is illustrated using the bold solid line. The liquid fraction variation during the heating

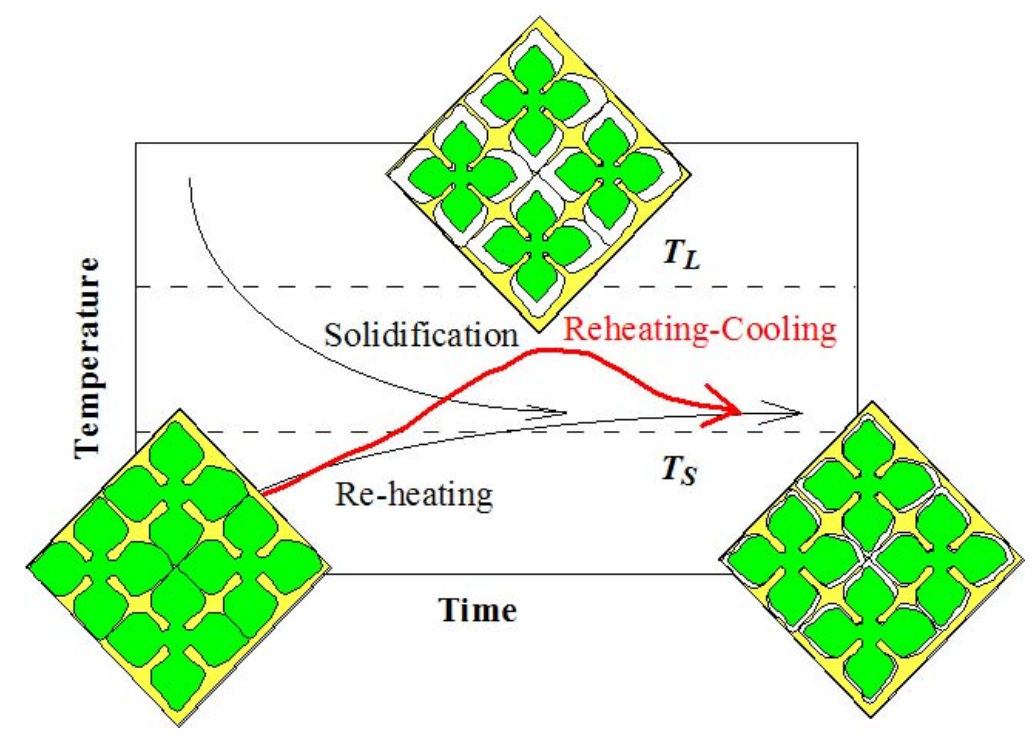

Fig. 4.3.1. Schematic illustration of the reheating-cooling method. The method combines the advantages of the reheating and solidification methods and is more suitable for measuring mechanical properties in the nonequilibrium mushy zones of alloys.

and cooling stages of the RCM is also illustrated. In RCM, the specimen is heated to a temperature corresponding to a liquid fraction less than 0.5 and then cooled quickly to the desired temperature for mechanical property measurements. When the specimen is heated to a temperature higher than the nonequilibrium solidus temperature, liquid starts to form at the grain boundaries and the interdendritic regions. As a result, the grains become smaller, but the number of grains does not change if the liquid fraction is small. Both the reheating and cooling stages of the RCM have important differences compared with the traditional reheating and solidification methods. During the reheating stage, the heating rate is high to minimize back diffusion in the solid. During the cooling stage of the new method, the grains grow back to their original size and even recover the solute redistribution produced during solidification. In contrast to the solidification method, the grain size will be small if the grain size in the original specimen is small. This is because the number of grains in the specimen does not change during the reheating 
and cooling stages of the experiment. Thus, RCM combines the advantages of the traditional reheating and solidification methods. As a result, RCM is more suitable for testing the mushy zone mechanical properties of fine-grained castings, such as those produced by DC and diecasting processes. It is also experimentally simpler than the traditional solidification method.

\subsubsection{Apparatus}

An illustration of the experimental apparatus is shown in Fig. 4.3.2. Tensile tests were conducted on an Instron 4507 machine with a $5 \mathrm{kN}$ load cell. The specimen was heated using an infraredlamp furnace. The infrared lamps were chosen for their rapid heating and cooling capability. Cooling was accomplished by simply turning off the lamps, since the furnace housing was watercooled. The furnace consisted of two rectangular water-cooled housings measuring $6 \times 4 \times 3.5$ in. each. Four IR-lamps were placed in each housing for a maximum rating of $5 \mathrm{~kW}$. A programmable multi-segment YOKOGAWA furnace controller allowed specimens to be heated up and cooled according to a prescribed user program.

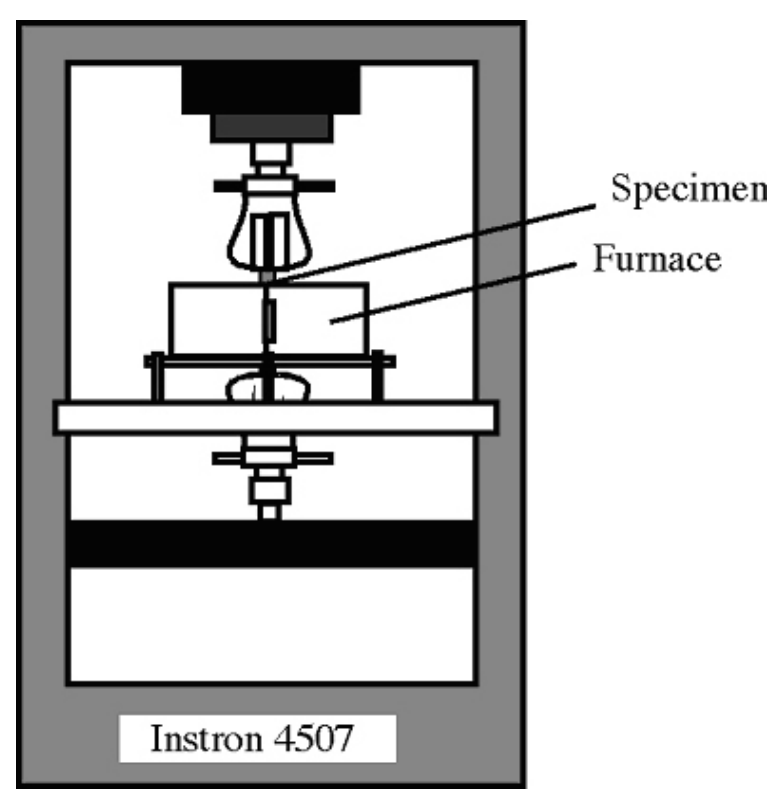

(a)

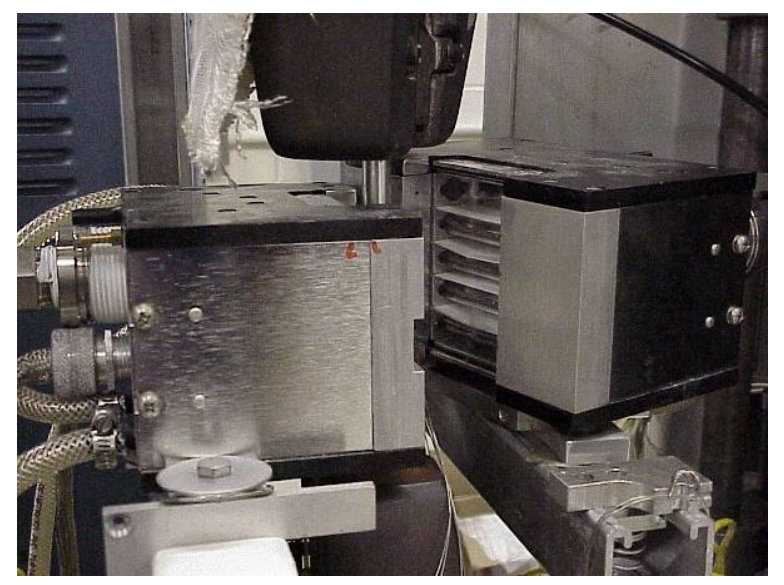

(b)

Fig. 4.3.2. The mechanical testing apparatus: (a) schematic illustration of test apparatus; (b) photo of the infrared furnace and the tensile specimen.

The specimen used for the tests is shown in Fig. 4.3.3. The specimen geometry was selected so as to minimize the radial temperature gradient and obtain an isothermal section in the middle of the gauge section. The strain was measured in the isothermal section of the specimen using an extensometer. The specimens were cut from the steady-state region of an aluminum alloy 3004 DC cast ingot with overall dimensions of $28 \times 73 \times 300$ in. The nominal composition of aluminum alloy 3004 is given in Table 4.2.1. In the region from which the samples were taken, the grain size was about $400 \mu \mathrm{m}$, and the secondary dendrite arm spacing was about $100 \mu$ 

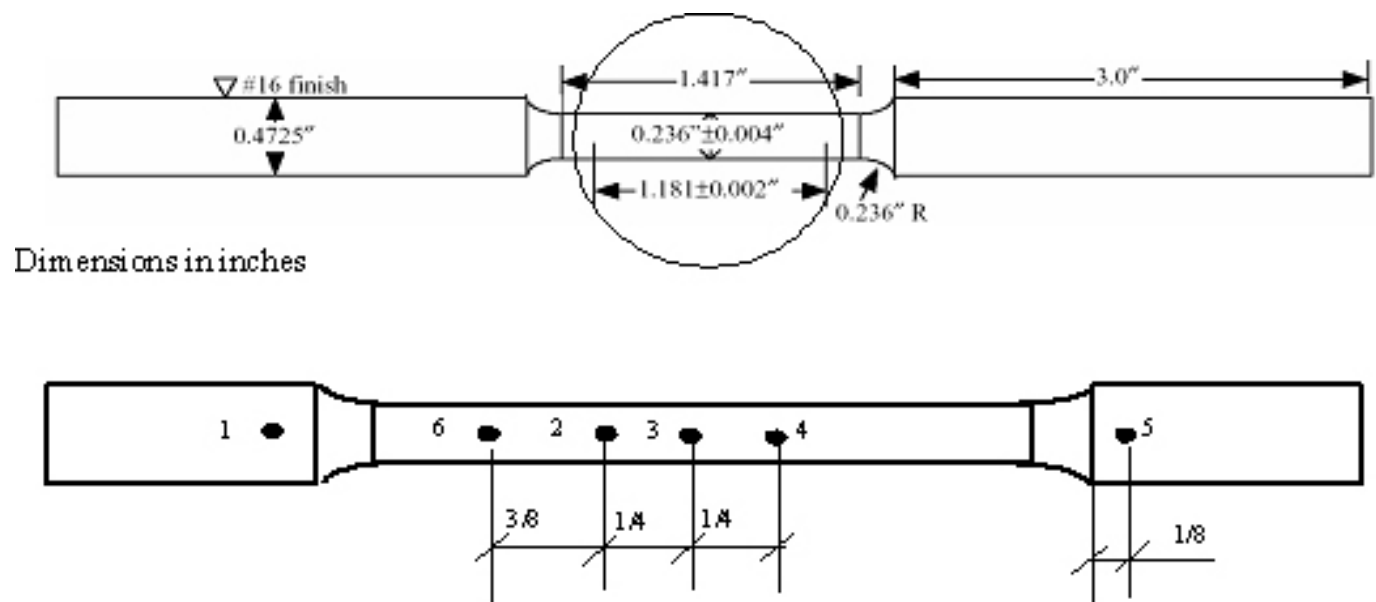

Fig. 4.3.3. The specimens used for the measurement of mechanical properties in the nonequilibrium mushy zone temperatures.

\subsubsection{Experimental Conditions}

In order to determine the experimental conditions, the temperature vs solid fraction curve for aluminum alloy 3004 shown in Fig. 4.2.7 was used. The liquidus temperature of the alloy is $649^{\circ} \mathrm{C}$. The equilibrium solidus temperature was calculated to be $624^{\circ} \mathrm{C}$, while the nonequilibrium solidus temperature under Scheil condition can be as low as $450^{\circ} \mathrm{C}$, the eutectic temperature of binary aluminum-magnesium alloys. In practice, the nonequilibrium solidus temperature will depend on the cooling rate and the extent of back diffusion.

For tensile tests in the mushy zone, the specimens were heated to $630^{\circ} \mathrm{C}$, which is $6^{\circ} \mathrm{C}$ higher than the equilibrium solidus temperature and corresponds to a liquid fraction of 0.2 , and then cooled to the test temperature. As the temperature vs solid fraction curve is relatively steep at $630^{\circ} \mathrm{C}$, the margin for error is less than at higher temperatures.

\subsubsection{Temperature Control}

The temperature profile along the specimen was measured using Type K thermocouples placed at six locations along the specimen, as shown in Fig. 4.3.3. Calibration curves were obtained using the thermocouple at location 3 as the control thermocouple. The thermocouple at location 6 was used for temperature control during the tensile tests. The data was collected using a 16channel data acquisition unit at a sampling rate of $10 \mathrm{~Hz}$.

Typical temperature vs time curves obtained using location 6 as the control thermocouple are shown in Fig. 4.3.4. The center of the specimen was heated to $400^{\circ} \mathrm{C}$ in $30 \mathrm{~s}$, held at $400^{\circ} \mathrm{C}$ for 3 min, then heated from 400 to $630^{\circ} \mathrm{C}$ at maximum power, and immediately cooled to the test temperature. The isothermal hold at $400^{\circ} \mathrm{C}$ was used to equilibrate the specimen. Solute diffusion at this stage should be negligible, since the temperature is relatively low. Heating rates from room temperature to $400^{\circ} \mathrm{C}$ were almost linear. However, heating rates from 400 to $630^{\circ} \mathrm{C}$ were nonlinear, due to the presence of latent heat of melting. Interestingly, the nonlinearity in the heating curves occurs around $450^{\circ} \mathrm{C}$, suggesting that the nonequilibrium solidus temperature is close to $450^{\circ} \mathrm{C}$. 


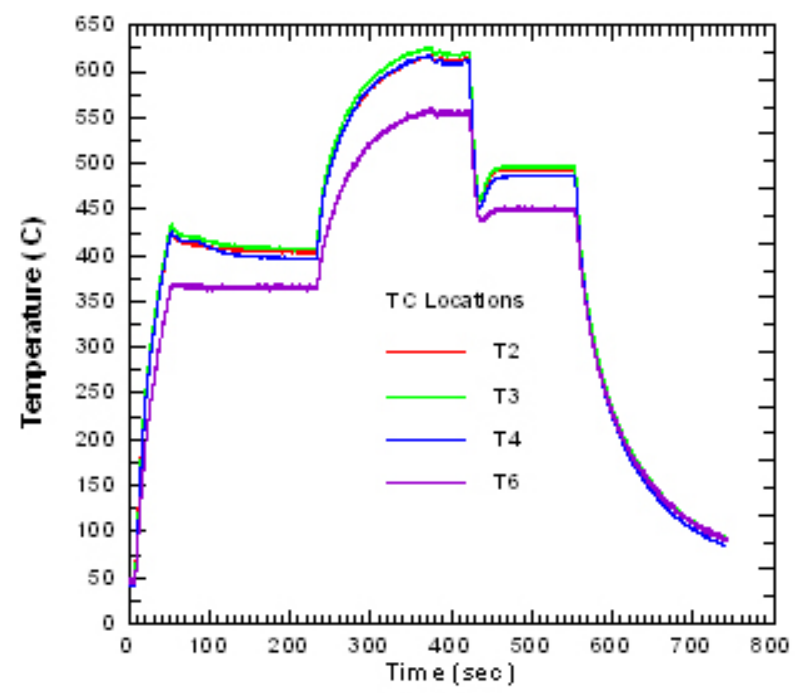

Fig. 4.3.4. Temperature profiles obtained using location 6 as the control thermocouple.

The relationship between the temperature at location 6 and the temperatures at locations 2, 3, and 4 is plotted in Fig. 4.3.5. The relationship is linear. The temperature difference between locations 2, 3, and 4 was smaller than $10^{\circ} \mathrm{C}$. From Fig. 4.2 .7 we find that when the temperature of the alloy is about $600^{\circ} \mathrm{C}$, the liquid fraction variation is fairly small-around $2.5 \%$, for a temperature variation of $10^{\circ} \mathrm{C}$. Fig. 4.3.5 was used in experiments for temperature control.

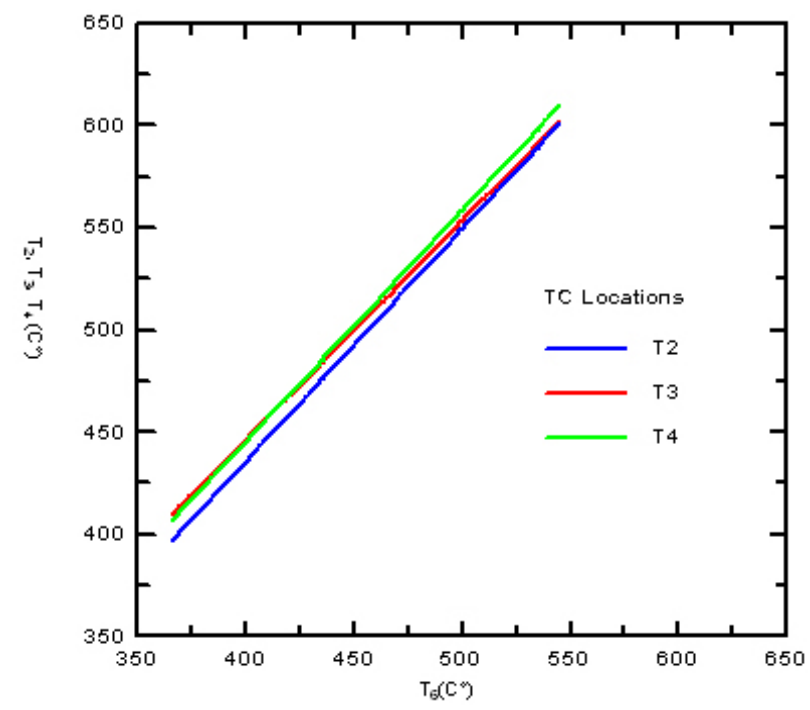

Fig. 4.3.5. The calibration curves used for RCM. The temperature differences at locations 2,3 , and 4 were smaller than $10^{\circ} \mathrm{C}$, indicating that the temperature was fairly uniform in the gauge length of the tensile specimen.

\subsubsection{Results and Discussion}


Figure 4.3.6 shows three stress-strain curves obtained at $600^{\circ} \mathrm{C}$ under three different conditions: heating, cooling from $620^{\circ} \mathrm{C}$, and cooling from $630^{\circ} \mathrm{C}$. In the first case, the specimen was heated to $600^{\circ} \mathrm{C}$ in $8 \mathrm{~min}$. In the other two cases (i.e., RCM) the specimens were quickly heated to mushy zone temperatures and then cooled to $600^{\circ} \mathrm{C}$ for testing. The top curve was obtained using the heating method. It shows that the specimen was quite ductile. The bottom curve was obtained using RCM, which correctly captured the brittle nature of the material at $600^{\circ} \mathrm{C}$, which is $24^{\circ} \mathrm{C}$ lower than the equilibrium solidus temperature of the alloy. Both the stress-to-fracture and the strain-to-fracture values using RCM are much smaller than those obtained using the heating method. Reheating to $620^{\circ} \mathrm{C}$ captured the low stress-to-fracture value, but the specimen was still quite ductile, possibly because there was insufficient liquid at $620^{\circ} \mathrm{C}$, and because back diffusion is rapid at temperatures below the equilibrium solidus temperature of $624^{\circ} \mathrm{C}$.

Figure 4.3.7 shows the stress-strain curves obtained using RCM for a test temperature of $615^{\circ} \mathrm{C}$ with varying holding times. Specimens were reheated to $630^{\circ} \mathrm{C}$, cooled to $615^{\circ} \mathrm{C}$, and held at $615^{\circ} \mathrm{C}$ for 0,1 , and $8 \mathrm{~min}$ before testing. The specimens exhibited little ductility at short holding times ( 0 and $1 \mathrm{~min}$ ) but exhibited significant ductility at long holding times (8 min). At long holding times, the stress-strain curves are similar to those obtained using the reheating method. This suggests that substantial back diffusion occurs in the reheating method, resulting in fictitiously high mechanical properties. The results shown in Fig. 4.3.7 suggest that the reheating method is unsuitable for

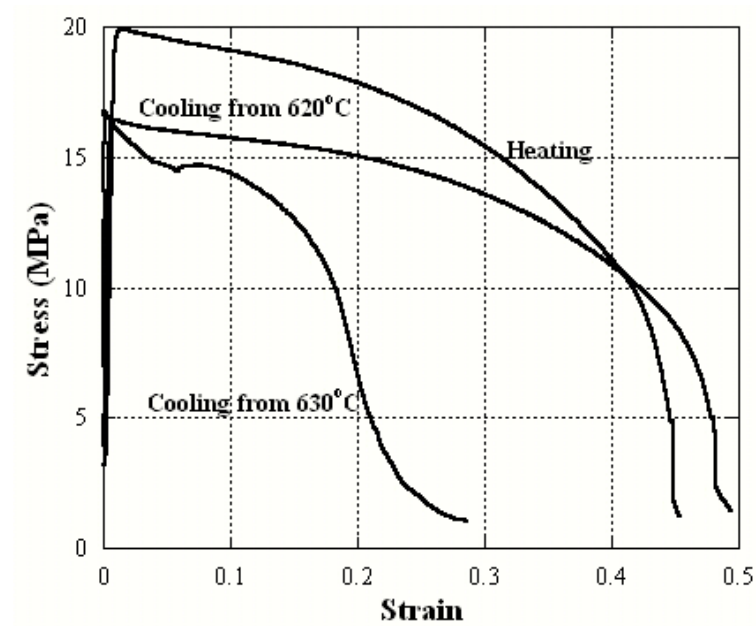

Fig. 4.3.6. Comparison of the stress-strain curves obtained using the reheating method and RCM. RCM (bottom curve) captured the brittle nature of the alloy at $600^{\circ} \mathrm{C}$, while the curve obtained using the reheating method (top) indicated significant ductility.

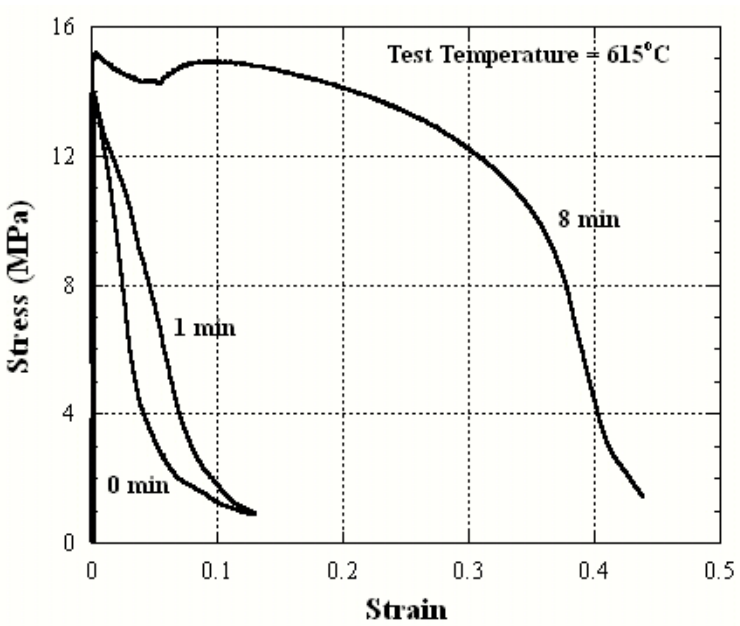

Fig. 4.3.7. Stress-strain curves obtained using RCM at holding times of $\mathbf{0 , 1}$, and $\mathbf{8} \mathrm{min}$. Holding time has a significant effect on the resulting mechanical properties.

measuring mechanical properties in the nonequilibrium mushy zones of alloys. This is because the holding time in the reheating method starts from the instant the temperature is equal to the nonequilibrium solidus temperature of the alloy. In RCM, a large portion of the solid is remelted in the reheating stage so that back diffusion in the solid is not significant. During cooling, the grains grow back to their original size and even recover the original solute redistribution. 
Substantial back diffusion can occur only after the specimen has been cooled to the test temperature. As a result, the holding time in RCM is much shorter than in the reheating method.

Scanning electron microscopy (SEM) was used to observe the fracture surfaces of specimens tested at $615^{\circ} \mathrm{C}$ using RCM and the reheating method. Figures 4.3.8(a) and (b) are low- and highmagnification SEM fractographs of a specimen tested using RCM. Figures 4.3.8(c) and (d) are SEM fractographs of a specimen tested using the reheating method. A comparison of (b) and (d) indicates that the RCM specimen failed primarily by cleavage, while the specimen tested using the reheating method failed in a more ductile manner. This is consistent with the mechanical testing results shown in Figs. 4.3.6 and 4.3.7. The smooth regions in Fig. 4.3.8(b), which are dendrite boundaries containing a solidified layer of interdendritic liquid, confirm the presence of an intergranular liquid phase at the point of failure. The fracture surface of the specimen tested using the reheating method, shown in Fig. 4.3.8(d), exhibits far fewer smooth regions or evidence of cleavage fracture. Clearly, more liquid phase was present in the specimen tested using RCM than in that tested using the reheating method. This indicates that RCM is better at limiting the decrease in interdendritic liquid fraction due to back diffusion during heating, isothermal holding, and testing, and is more suitable for the measurement of mechanical properties in the nonequilibrium mushy zones of alloys.

The reheating-cooling method developed in this project was used for measuring the mechanical properties of aluminum alloys at nonequilibrium mushy zone temperatures. Figure 4.3.9 shows the tensile strength data of aluminum 3004 alloys as function of strain rates and temperatures. The tensile strength of the alloy at the nonequilibrium mushy zone temperature range decreases sharply with increasing temperature and decreasing strain rate. The tensile strength data are used in a criterion for crack (hot tearing) formation during DC casting of aluminum alloys.

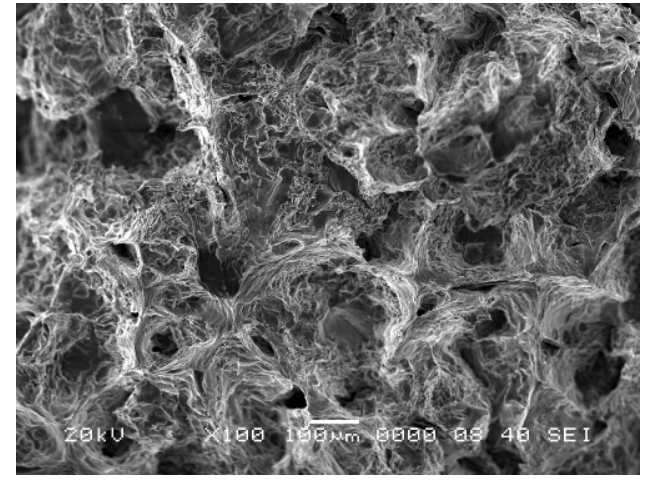

(a)

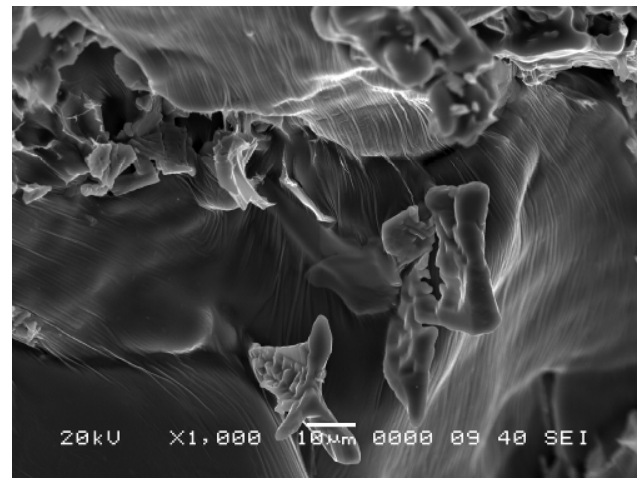

(b) 


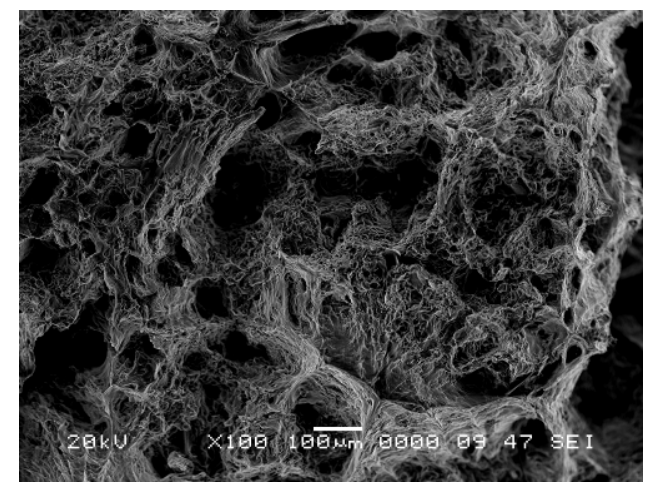

(c)

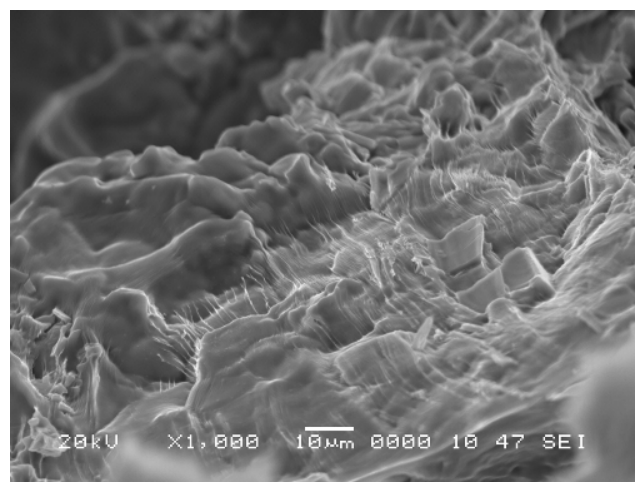

(d)

Fig. 4.3.8. Fracture morphologies of aluminum alloy 3004 specimens tested at $615^{\circ} \mathrm{C}$ using the reheating-cooling method $(a-b)$ and the reheating method (c-d).

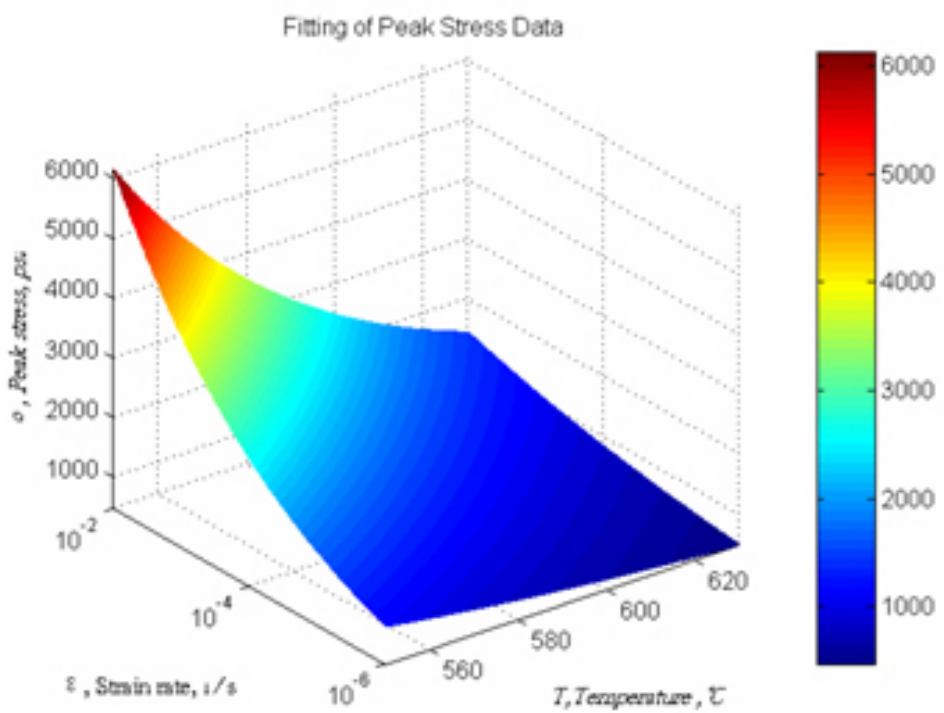

Fig. 4.3.9. The tensile strength of 04 alloy as a function of strain rate and temperature in the none rium mushy zone temperature. The results were obtained using the reneating-cooling method, newly developed in this project.

In summary, a new method, termed the reheating-cooling method (RCM), has been developed and validated for the measurement of mechanical properties in the nonequilibrium mushy zones of alloys. RCM consists of a reheating stage in which the alloy is heated above the equilibrium solidus temperature to remelt part of the grains, and a cooling stage in which the grains grow back to their original size and even recover the solute redistribution produced during solidification. The number of grains in the specimen does not change during the reheating and cooling stages of the experiment. As a result, RCM is more suitable for testing mushy-zone mechanical properties of fine-grained castings, such as those produced by DC and die-casting processes. It is also experimentally simpler than the traditional solidification method.

Experiments on aluminum alloy 3004 specimens using RCM indicate that the method captures the brittle nature of aluminum alloys at temperatures close to the nonequilibrium solidus 
temperature, while specimens tested using the reheating method exhibit significant ductility. RCM has been used for determining the mechanical properties of alloys at nonequilibrium mushy zone temperatures. Accurately data have been obtained in this project.

\subsection{Constitutive Models for Aluminum Alloy at High Temperatures}

\subsubsection{Introduction}

Appropriate constitutive relations describing the mechanical behavior of alloys from the solidus temperature to the ambient temperature are required for the simulation of stress-strain, and deformation in DC casting ingot. Few data are available in the literature on such constitutive models for aluminum alloys at elevated temperatures. As a result, part of the research effort was devoted to determining these relations.

There are different types of models describing the development of stress-strain inside solidified metal. The elasto-viscoplastic model in ProCAST software was used in this project. In this model the material will not return to its initial shape if loading exceeds yield strength. The stress will be a function of the strain and strain rate:

$$
\begin{aligned}
& y=\sqrt{\frac{3}{2}}(s: s)^{1 / 2}-K \\
& K=Y_{0}(T)+H(T) \overline{\varepsilon^{P}} \\
& \overline{\varepsilon^{P}}=\int_{0}^{t}\left(\frac{2}{3}(\dot{e}: \dot{e}) d \tau\right. \\
& \dot{e}=\frac{1}{\eta}\left(\frac{y}{Y_{0}}\right)^{m} \frac{\partial y}{\partial s}
\end{aligned}
$$

where $y$ is the yield function, $s$ is the deviatoric stress, $K$ is the hardening function, and $\eta$ is the viscosity.

The development of stress-strain behavior in solidifying metals is expected to change with changing temperature because of the cooling effect during solidification. Strain rate will generate as a direct result of the change of temperature with respect to time, as explained by the following formula:

$$
\dot{e}=\alpha \bullet \dot{T},
$$

where $\alpha$ is the coefficient of expansion. The data we have for the high temperature case were all conducted under the simple test condition. In a simple tension test the deviatoric stress $s$ is related to the Cauchy stress $\sigma$ by 


$$
s=\left[\begin{array}{ccc}
2 \sigma / 3 & 0 & 0 \\
0 & -\sigma / 3 & 0 \\
0 & 0 & -\sigma / 3
\end{array}\right]
$$

As a result, the constitutive models used in ProCAST yield the following relations:

$$
\begin{aligned}
& y=\sqrt{\frac{3}{2}}\left(6 \sigma^{2} / 9\right)^{1 / 2}-K=\sigma-K \\
& \frac{\partial y}{\partial s}=\frac{\partial y}{\partial \sigma}=1 \\
& \dot{e}=\frac{1}{\eta}\left(\frac{\sigma-K}{Y_{0}}\right)^{1 / m}=\frac{1}{\eta}\left(\frac{\sigma-Y_{0}-H(T) \overline{\varepsilon^{P}}}{Y_{0}}\right)^{1 / m} . \\
& \sigma=Y_{0}+H(T) \overline{\varepsilon^{P}}+Y_{0}(\eta \dot{e})^{1 / m}
\end{aligned}
$$

\subsubsection{Model Calibration from Experimental Data for}

Four variables must be determined to use this constitutive cyuuion: $m, H$, $\underline{\underline{\underline{\underline{I}}}}$ ad the viscosity $\eta$. The parameters are determined from experimental stress-strain data at diff $\ldots \ldots$ strain rates and temperatures. High-temperature tests were conducted at ORNL under a wide range of temperatures and strain rates. Stress-strain data were used to calibrate the model. The reheating method shown in Fig. 4.3.1 and discussed in Sect. 4.3 of this report was used for measuring the mechanical properties at temperatures below the solidus temperature of the alloy.

A plot of the $\operatorname{Ln} \sigma$ vs $\operatorname{Ln} \dot{e}$ is drawn from the experimental stress-strain data. The slope of each curve represents the strain rate sensitivity index, $m$. Figure 4.4.1 shows fitted linear lines for different temperatures. The values of $m$ as a function of temperature are listed in the table 


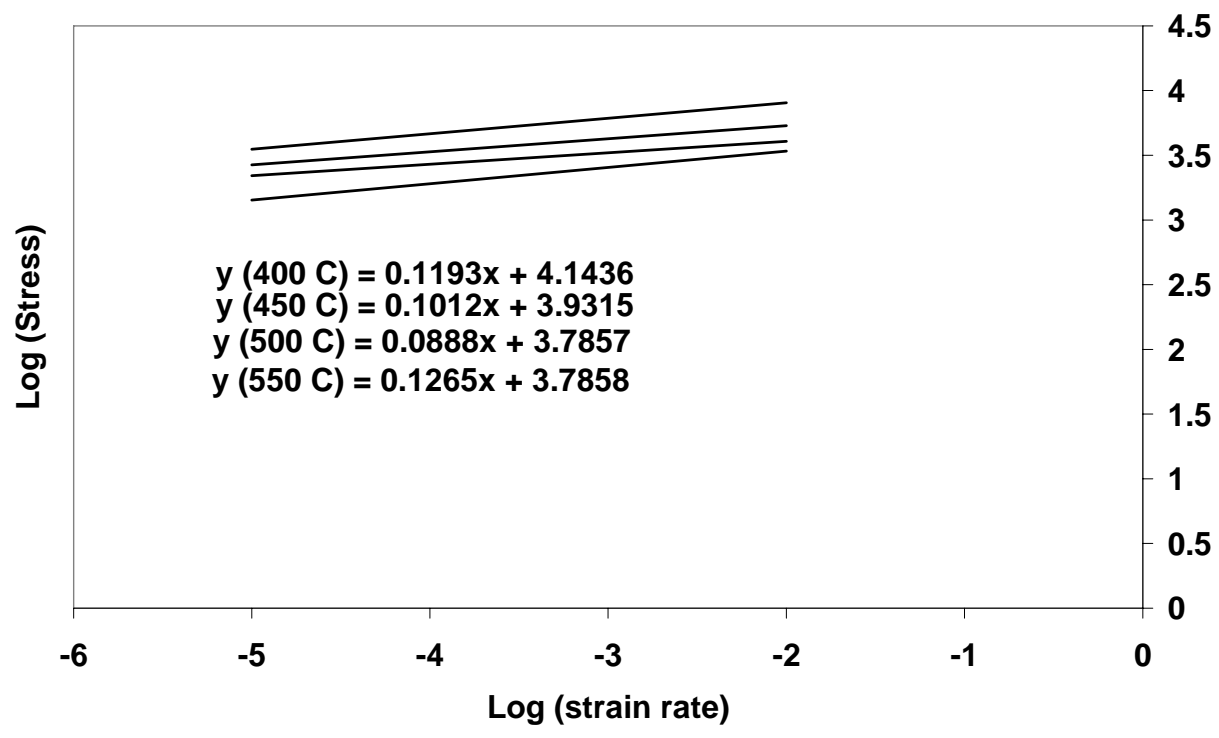

Fig. 4.4.1. Logarithmic plot of stress vs strain rate. 
The parameter $Y_{0}$ can be directly extracted from the stress-strain curve, and it represents the flow stress. The values of $H$ and of the viscosity, $\eta$, are empirically found by fitting the experimental data to the model. Table 4.4.1 summarizes all the variables needed to calibrate the model for aluminum alloy 3004 at different temperatures.

Table 4.4.1. Values of parameters of ProCAST model

\begin{tabular}{|c|c|c|c|c|}
\hline $\begin{array}{c}\boldsymbol{T} \\
\left({ }^{\circ} \mathbf{C}\right)\end{array}$ & $\begin{array}{c}\mathbf{H} \\
(\mathbf{T})\end{array}$ & $\boldsymbol{\eta}$ & $\mathbf{1 / m}$ & $\boldsymbol{Y}_{\mathbf{0}}$ \\
\hline 400 & 100 & $5 \times 10^{11}$ & 0.12 & 500 \\
\hline 450 & 100 & $22 \times 10^{11}$ & 0.1 & 450 \\
\hline 500 & 100 & $21 \times 10^{11}$ & 0.088 & 420 \\
\hline 550 & 100 & $5 \times 10^{11}$ & 0.08 & 400 \\
\hline
\end{tabular}

\subsubsection{Experimental Results and Discussion}

The experimental results are plotted against the model in Figs. 4.4.2-4.4.5 at different test temperatures. A reasonably good fit is achieved. As can be seen, increasing the temperature or slowing the strain rate tends to reduce the flow stress. In addition, at higher temperatures, the material does not exhibit hardening, and a drop in the flow stress with strain is an indication of softening. An interesting result can be seen from the graphs: at these relatively high temperatures, the ductility (elongation to failure) decreases by reducing the strain rate. This is due to significant cavitation developed during high-temperature deformation. The fracture surface was examined and cavitation was seen when tests were conducted at temperatures higher than $400^{\circ} \mathrm{C}$. The model is capable of predicting the stress-strain behavior at different strain rates and temperatures.

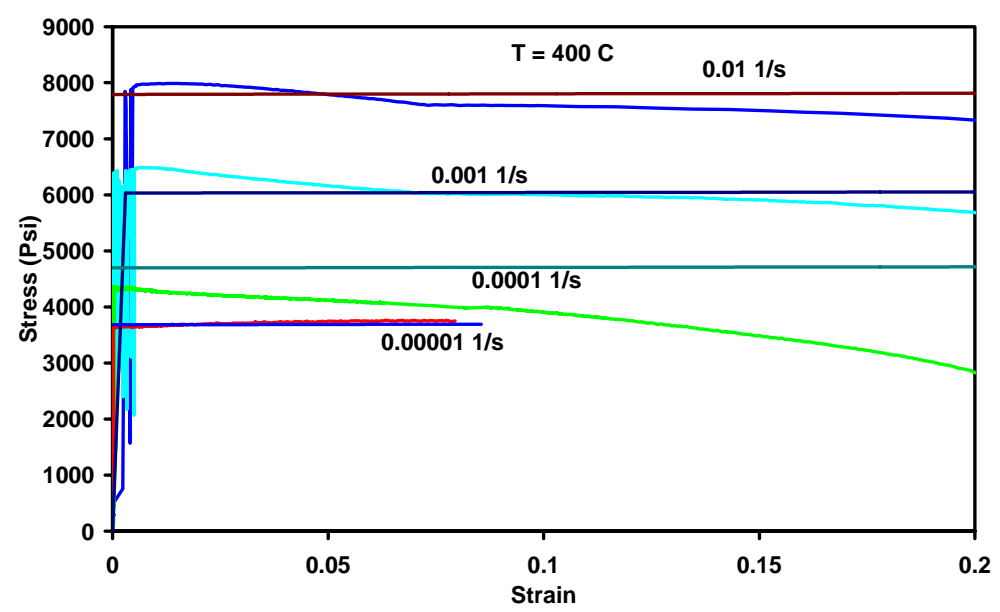

Fig. 4.4.2. Comparison of the experimental data with the model of Eq. (4.4.4) at $400^{\circ} \mathrm{C}$. 


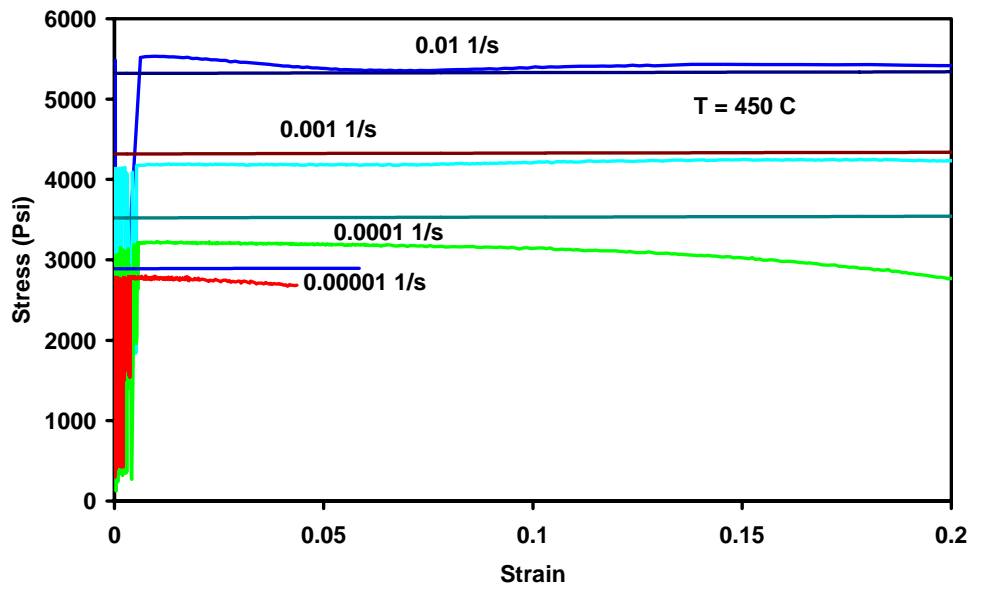

Fig. 4.4.3. Comparison of the experimental data with the model of Eq. (7.4) at $450^{\circ} \mathrm{C}$.

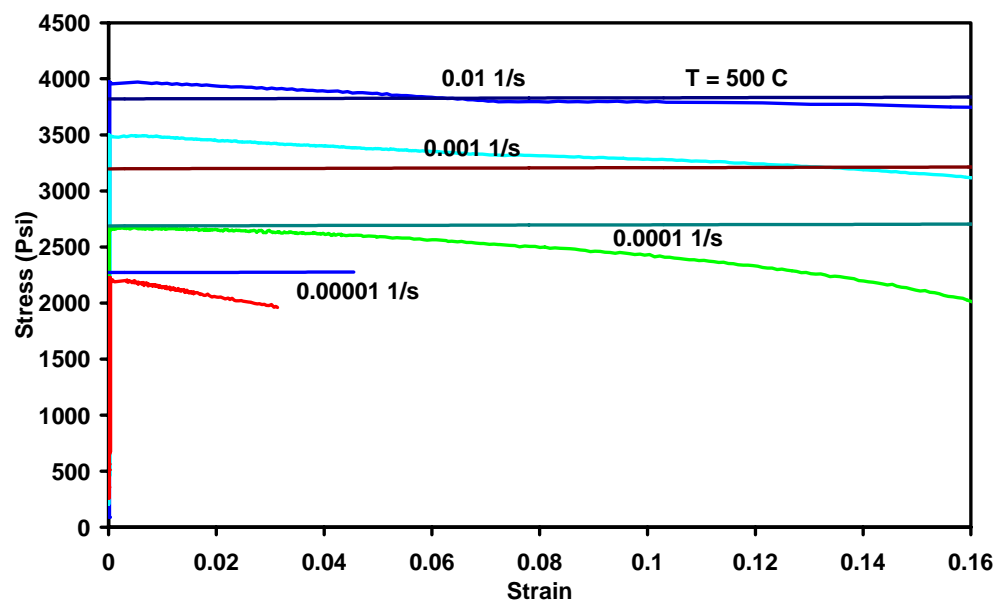

Fig. 4.4.4. Comparison of the experimental data with the model of Eq. (4.4.4) at $500^{\circ} \mathrm{C}$.

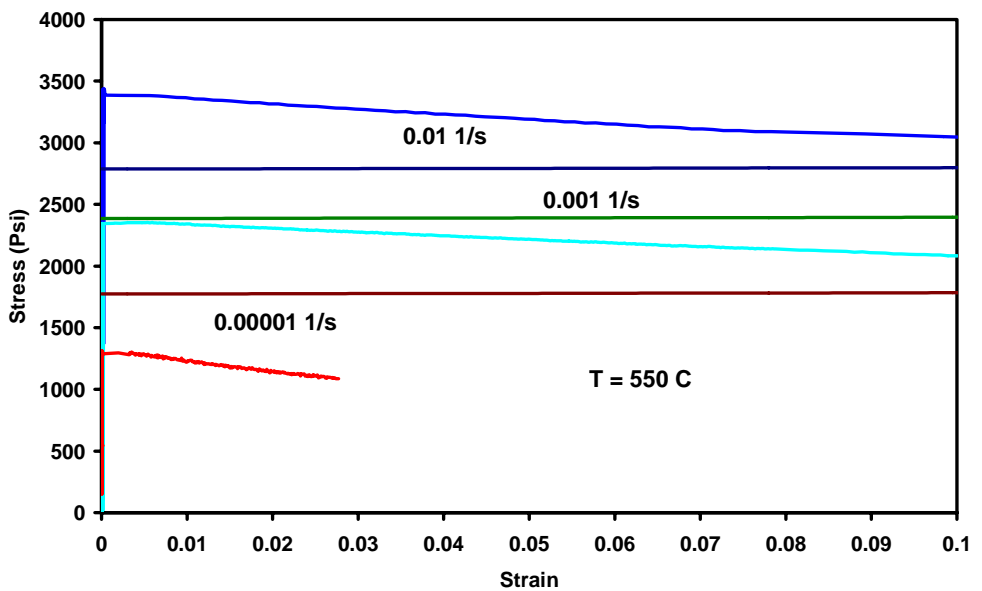

Fig. 4.4.5. Comparison of the experimental data with the model of Eq. (4.4.4) at $550^{\circ} \mathrm{C}$. 



\subsection{Modeling of Solidification and Stress-Strain Formation during DC Casting}

\subsubsection{Introduction}

A three-dimensional (3D) model has been developed for the simulation of solidification and stress-strain formation during DC casting. The modeling effort was initially begun with a code developed by ORNL for the solidification simulation and with ABAQUS for the stress and strain simulation. The purpose of the solidification simulation was to determine the effect of boundary conditions such as the water intrusion between the DC casting ingot and the end block and the uneven heat transfer at the corners of the DC casting ingot. Based on the initial simulation work, the effort was then directed towards the incorporation of the research results into the commercial software package ProCAST.

The integrated 3D model includes

- detailed descriptions of the extremely non-uniform heat removal at the ingot surface under industrial environments;

- $\quad$ simulation of the fluid flow, temperature and stress fields, and the evolving solidification microstructure; and

- detailed description of material behavior at elevated temperatures.

In particular, the HTCs measured in this project and obtained in the literature were applied at the surfaces of the ingot. The constitutive relations of the mechanical behavior of the alloy were integrated into the stress-strain module of ProCAST. Material properties as function of temperatures were also predicted and incorporated into the 3D model. The model predictions were validated with the temperature measurements obtained in commercial-scale casting trials. The integrated 3D model can be used to discuss parameters that affect hot tearing formation in the DC casting process. These parameters include the casting temperature, the casting speed, the flow rate of the cooling water, and the temperatures of the mold and the bottom

\subsubsection{The Solid Model}

Figure 4.5.1 shows the geometry and mesh of the ingot, the mold, and the bottom block. An ingot height of $760 \mathrm{~mm}$ was used for the DC casting model. Due to its symmetry, only onequarter of the geometry was used as the simulation domain. Eight-noded isoperimetric brick elements were used for the entire mesh of the ingot, block, and mold. The elements and nodes were 40240 and 45762, respectively.

\subsubsection{Initial Conditions and Boundary Conditions}

The initial temperatures of the mold and the bottom block were set to 20 and $50^{\circ} \mathrm{C}$, respectively based on the measured temperatures. The ingot was allowed to fill at the same rate as the casting speed. The initial temperature of the ingot was assumed to be $670^{\circ} \mathrm{C}$, which was the same as the pouring temperature. 


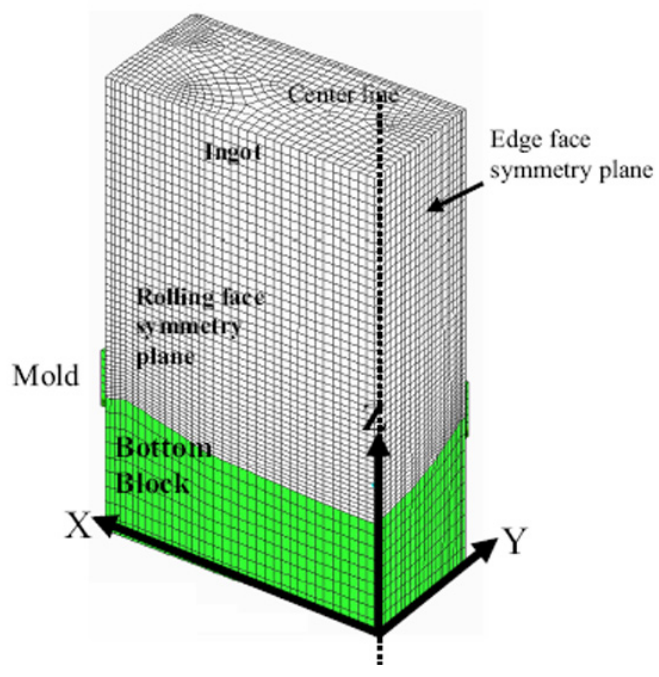

Fig. 4.5.1. The geometry and mesh of a quarter of an ingot, mold, and bottom block.

A constant HTC was used to calculate the heat transfer between the liquid metal and the mold. The effects of the air gap formed during casting on the HTC between the bottom block and the curled portion of the ingot was considered in this model. A constant HTC of $100 \mathrm{~W} / \mathrm{m}^{2}-\mathrm{K}$ was used to calculate the heat transfer in the air gap at the mold corner and just below the mold.

Temperature-dependent HTCs were developed for water cooling based on the temperature measurements performed in the commercial-scale casting facility. A 2D inverse model in ProCAST was used to obtain the HTCs, which are shown in Fig. 4.1. that presented by Sengupta [33], and also has the same trend as that L... jy Bagnoud [ shown in Fig. 4.1.8, all of heat transfer features between the cooling water and the hot i surface during the DC casting process (forced convection, nucleate boiling, the Leiden frost point, and film boiling) are represented.

In the water intrusion regions, the ingot and the bottom block are in contact with a mixture of water, water vapor, and air. The heat flux per unit area was computed on the basis of a weighted area average of the heat fluxes due to water and air using the following relationship:

$$
q_{\mathrm{int}}^{\prime \prime}=f_{w c} h_{w}\left(T, W_{\mathrm{int}}, W_{o}\right)\left(T-T_{s w}\right)+\left(1-f_{w c}\right) h_{a}(T)\left(T-T_{s a}\right),
$$

where

$f_{w c}=$ fractional area in contact with water

$h_{w}\left(T, W_{\text {in }}, W_{o}\right)=$ HTC corresponding to the water intrusion flow rate, $W_{\text {int }}$, at the surface temperature $T$,

$T_{s w}=$ sink temperature used to compute the water heat flux

$h_{a}(T)=$ HTC at the surface temperature $T$

$T_{s a}=$ sink temperature used to compute the air heat flux.

For the case in which the sink temperatures are taken to be the same, i.e., $T_{s w}=T_{s a}=T_{s}$, the HTC in water intrusion areas becomes 


$$
h_{w, i}\left(T, W_{\mathrm{int}}, W_{o}\right)=f_{w c} h_{w}\left(T, W_{\mathrm{int}}, W_{o}\right)+\left(1-f_{w c}\right) h_{a}(T) .
$$

It is now assumed that the intruding water flow rate is a fraction, $f_{w}$, of the water flow rate on the rolling face, $W_{R}$, or end face, $W_{E}$, respectively:

$$
W_{\text {int }}(t)=\left\{\begin{array}{l}
f_{w} W_{R}(t) \text { water intrusion close to rolling faces, } \\
f_{w} W_{E}(t) \text { water intrusion close to end faces. }
\end{array}\right.
$$

At the bottom surface, it is assumed that the water intrudes from both the end and the rolling faces. As a first approximation, it is assumed that the HTC is the average between the HTC due to water intrusion from the rolling face, $h_{w, i}^{R}$, and that from the rolling faces, $h_{w, i}^{E}$ :

$$
h_{w, i}^{B}=f_{W E} h_{w, i}^{E}\left(T, W_{\mathrm{int}}^{E}, W_{o}\right)+\left(1-f_{W E}\right) h_{w, i}^{R}\left(T, W_{\mathrm{int}}^{R}, W_{o}\right)
$$

In this study, $f_{w c}=0.3, f_{w}=0.3, f_{W E}=0.8$, and $T_{s}=25.0$.

For the region on the bottom surface without drain holes-i.e., in the center of the ingot-only water from the rolling faces is considered to intrude.

\subsubsection{Material Properties}

The temperature-dependent thermal and physical properties used in the model-thermal conductivity, specific heat, density, coefficient of thermal expansion, latent heat, Young's modulus, and Poisson ratio-were either obtained from the ASM Handbook or calculated using JMatPro software, a thermodynamic calculation software developed by Thermotech, Ltd [ The liquidus temperature, the nonequilibrium solidus temperature, and the fraction solid $\mathrm{v}_{\mathrm{i}}$ temperature curve shown in Fig. 4.2.7 were calculated using ThermoCalc.

The thermally induced strain and stress were calculated on the basis of the calculated temperature distribution and the thermal coefficient of the materials. The relationship between the thermally induced strain and stress were determined using an elasto-viscoplastic material constitutive model [Eq. (4.4.4)]. The temperature-dependent parameters such as yield stress and the isotropic hardening coefficient were obtained through mechanical tests that were performed in the temperature range from room temperature to mushy zone temperature. An ingot cracking index (ICI), which represents the ingot cracking propensity, was established based on the ratio of stress to strength. The stress was calculated using the DC casting model, and the strength were measured from high-temperature mechanical property data.

\subsubsection{Validation of 3D Casting Model}

The commercial finite element modeling code ProCAST was used to set up the 3D DC casting model. The model includes heat transfer, fluid flow, solidification, and stress evolution. Key DC casting factors such as the variation of HTC as a function of ingot surface temperature, air gap between the mold and ingot, air gap between the bottom block and solidified ingot, and edge face symmetry plane were also considered in this model. 
Figure 4.5.2 illustrates temperature contours $\left({ }^{\circ} \mathrm{C}\right) 800 \mathrm{~s}$ after the start of pouring as predicted by the model. The pouting temperature was $670^{\circ} \mathrm{C}$, and the liquidus and solidus temperatures were $650^{\circ} \mathrm{C}$ and $535^{\circ} \mathrm{C}$, : ctively. A deep liquid sump in can be seen in the center of the ingot in Fig. 4.5.2. Also, th _...d skin thickness is still relatively small.

Figure 4.5.3 shows measured and calculated temperatures at two locations in the ingot as a function of time. Location 1 (8, 200, $; 75 \mathrm{~mm}$ from the surface, and location $2(8,200,218)$ is close to the center and $218 \mathrm{~mm}$ fro... a surface. Both locations are $200 \mathrm{~mm}$ from the ingot bottom and $8 \mathrm{~mm}$ off the Y-Z center plane. The close agreement between the calculated and measured temperatures demonstrates the validity of the solidification model.

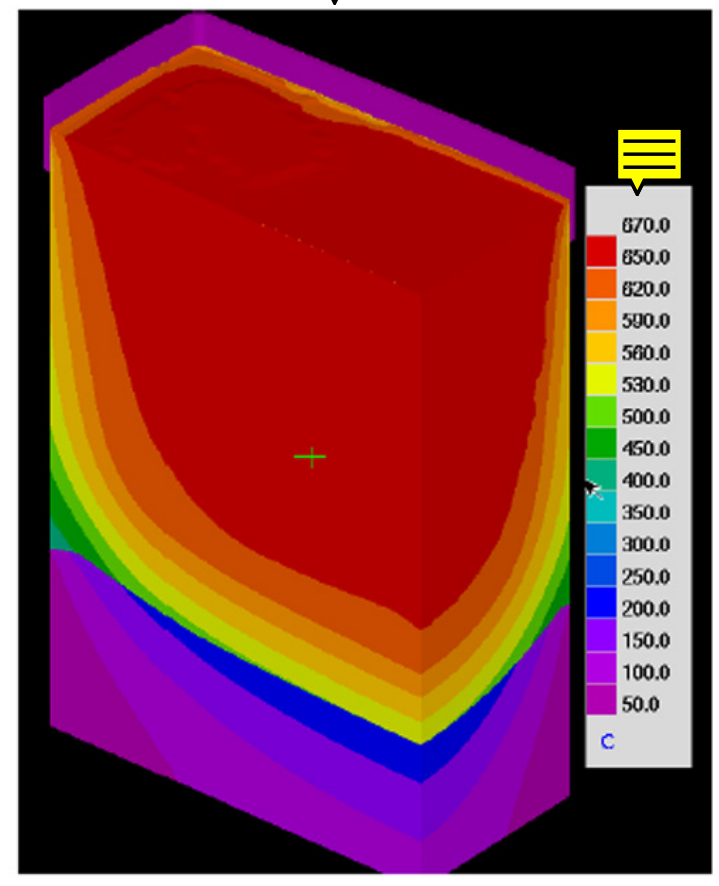

Fig. 4.5.2. Temperature contours $800 \mathrm{~s}$ after the start of pouring as predicted by the model. 


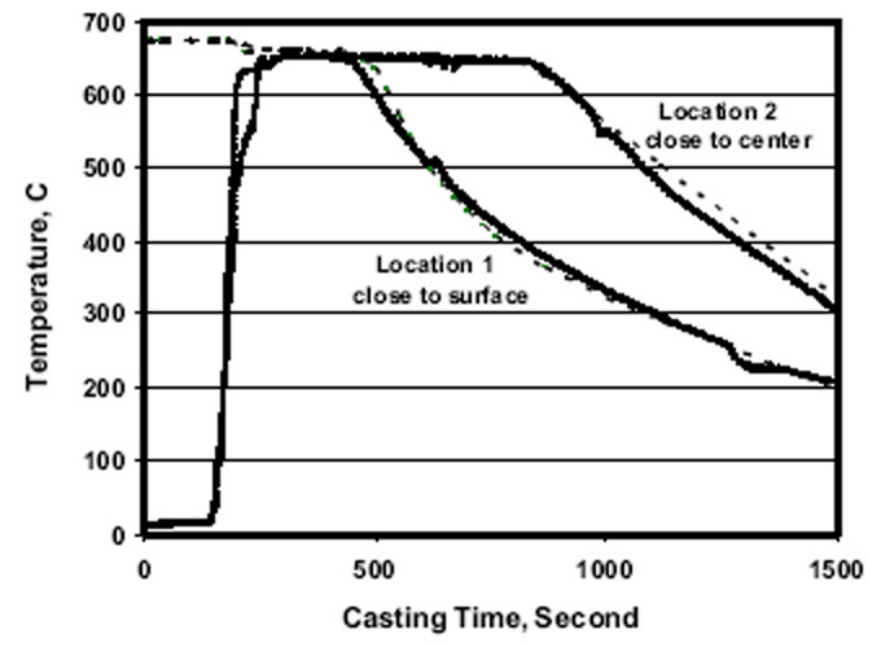

Fig. 4.5.3. Calculated and measured temperature profiles at locations near the surface and center. Solid lines indicate measurements, and dashed lines indicate predications.

Figure 4.5.4 shows the butt curl for half, normal and double casting speeds for an ingot height of $760 \mathrm{~mm}$. The results indicate that the butt curl increases as the casting speed increases. The extent of butt curl could reflect the ingot hot cracking propensity for certain alloys. Generally, it is believed that higher casting speeds lead to a higher hot cracking propensity. This suggests that the model can be used to predict the hot cracking propensity.

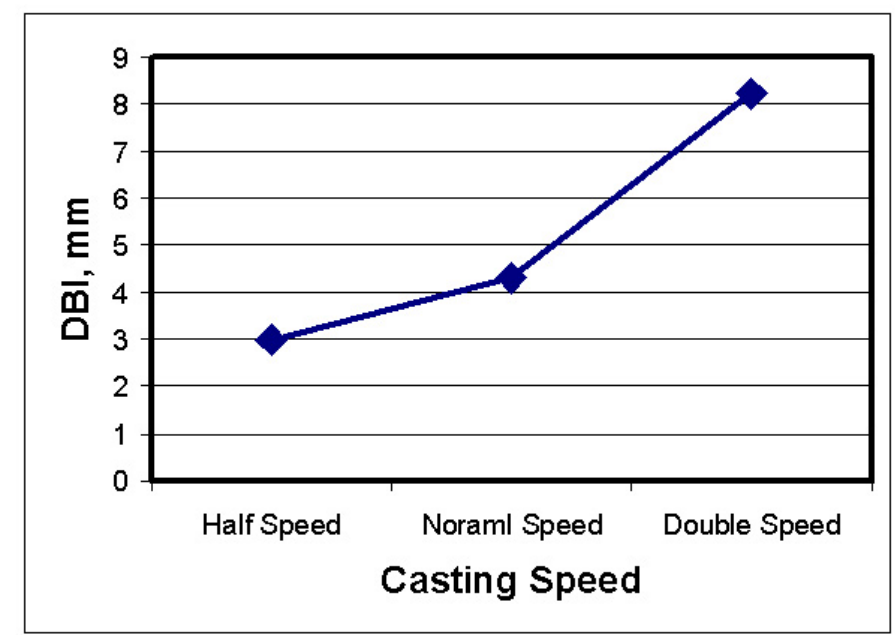

Fig. 4.5.4. Calculated butt curl distance plotted as a function of casting speed.

\subsubsection{Stress and Strain Analysis}

The stress-strain induced during casting is very complex due to the complex cooling conditions. Geometry also has a large effect on stress. Hot cracking usually initiates near the ingot surface and at mushy zone temperatures. Therefore, the stress analysis was monitored at locations near the ingot surface. Four locations situated 25, 50, 75, and $145 \mathrm{~mm}$ from the rolling surface were selected; and the solid fraction, temperature, stress, and strain at these locations were monitored. The coordinates of these four locations were (450, 320, 200), (450, 295, 200), (450, 270, 200), 
and (450, 200, 200). Figures 4.5.5-4.5.8 show the temperature, solid fraction, stress, and strain rate, respectively, as a function of casting time at these four locations. Locations closer to the surface tend to cool faster. Similarly, the solid fraction increases faster at locations closer to the ingot surface. Overall, the stress and the strain rate are highest at the location closest to the ingot surface.

An obvious reheating peak can be seen in Figure 4.5.5 at the surface location for a casting time of $300 \mathrm{~s}$. At the same time, the solid fraction at the surface is about 0.95 (Fig. 4.5.6), while peaks in stress and strain can be seen (Figs. 4.5.7 and 4.5.8). The reheating is caused by the air gap just below the mold and is an important contribution to ingot cracking. The low heat transfer in the air gap reduces the solidification rate in this area and causes reheating at locations close to the ingot surface. The reheating causes the material to be placed under tensile stress. Meanwhile, the material strength is greatly reduced at the higher temperatures. Consequently, reheating is very harmful and could cause ingot cracking during casting.
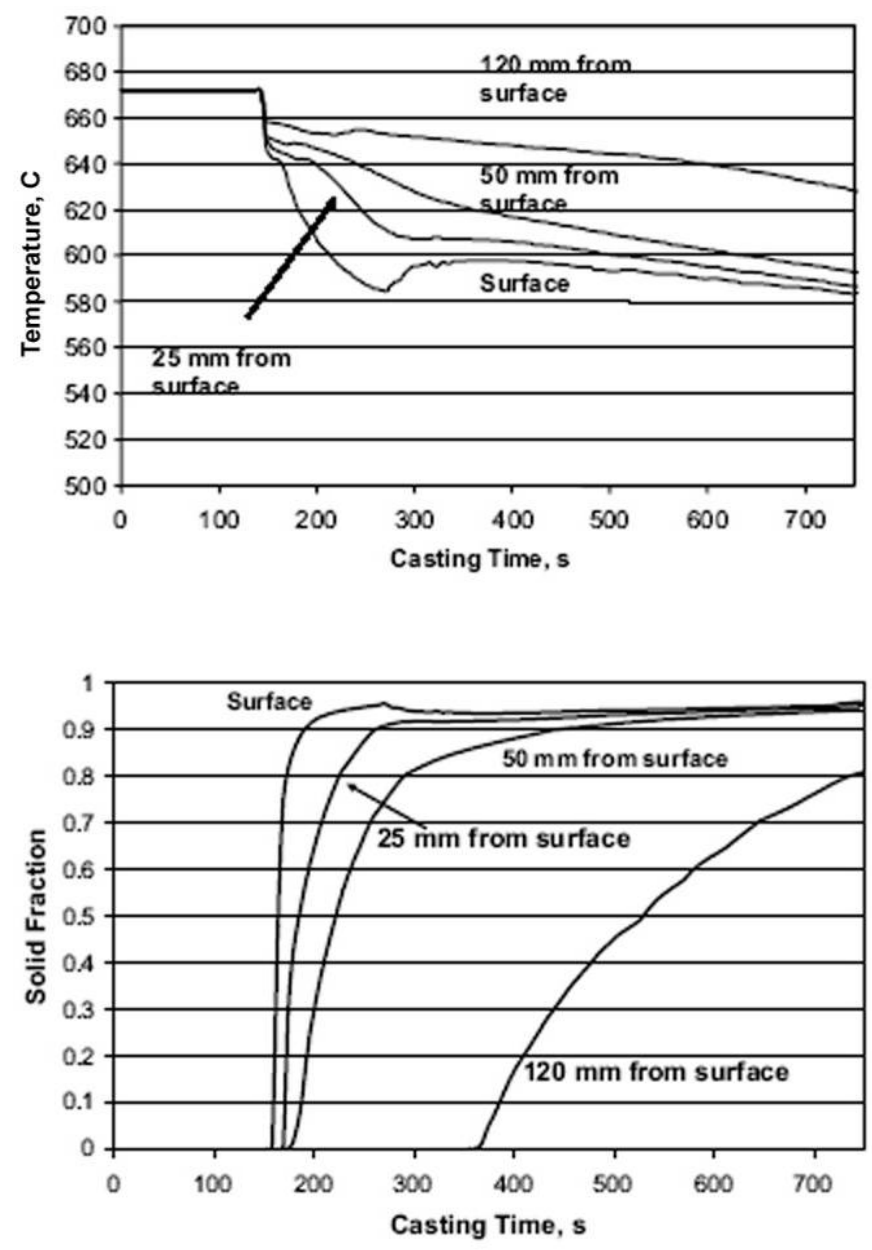

Fig. 4.5.5. Calculated temperature as a function of casting time for locations near the surface.
Fig. 4.5.6. Calculated solid fraction as a function of casting time for locations near the surface. 

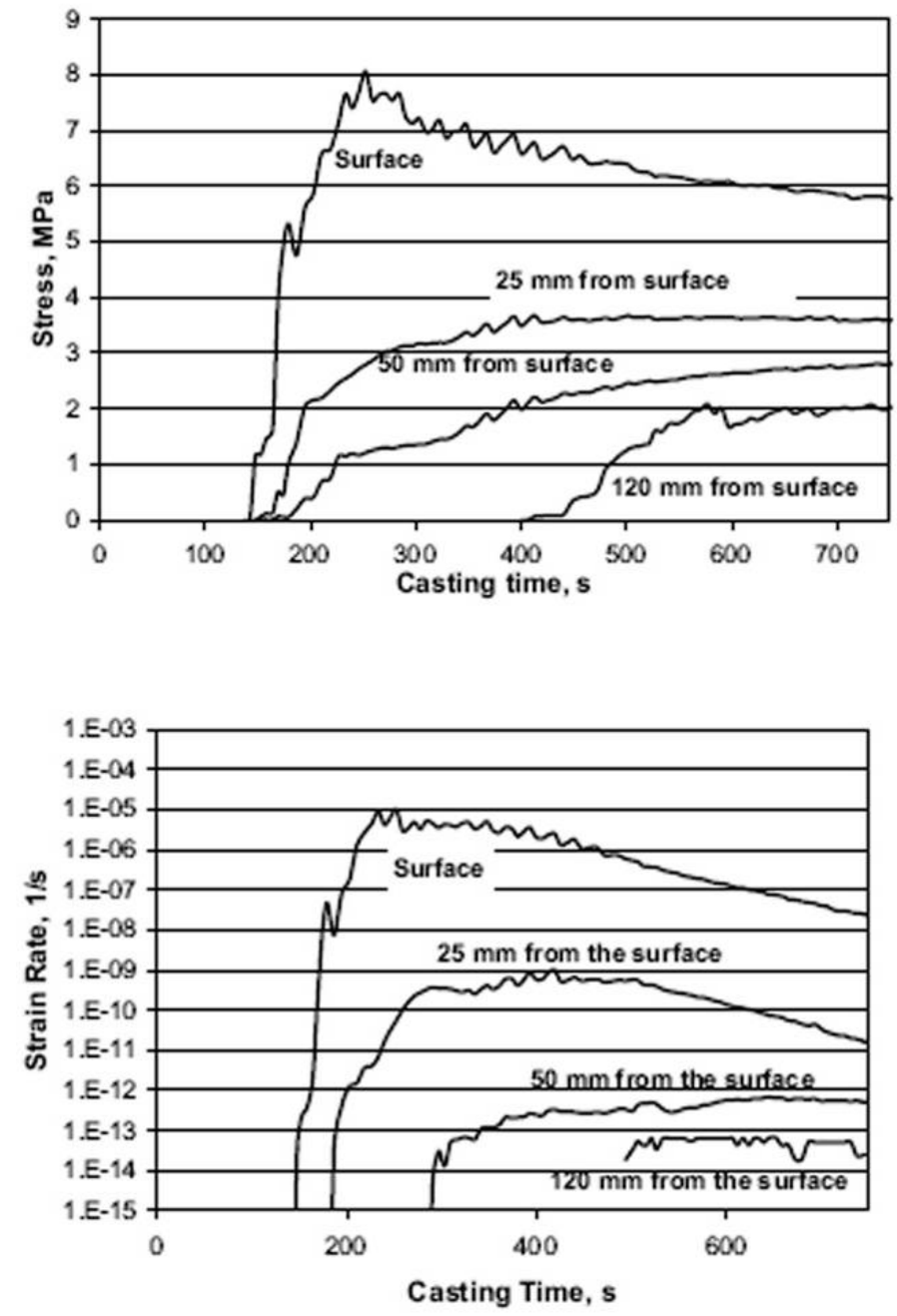

Fig. 4.5.7. Calculated stress as a function of casting time for locations near the surface.
Fig. 4.5.8. Calculated strain rate as a function of casting time for locations near the surface.

The calculated stress (Fig. 4.5.7) and strain (Fig. 4.5.8) distribution at 300 s after the start of DC casting indicates that high tensile stress-strain occurs at the surface of the ingot. This is true because the temperatures at the surface of the DC ingot are much lower than in the regions away from the surface. High tensile stress and high solid fraction are a harmful combination in terms of cracking formation because cracks formed at such a high solid fraction cannot be compensated for by liquid feeding.

It must be pointed out that the stress calculated by this model is still higher than the mechanical properties of the alloy at the corresponding temperatures, indicating inaccuracies in calculating the stress distribution. This is partly because the element sizes are still too large in the solid model. In fact, we have used the maximum element number the code can handle at the moment. More accurate stress simulation will depend on advances in both computer software and hardware. Much finer $\stackrel{p}{=}$ ents of the solid model need to be used for more accurate simulations. 
In summary, an integrated 3D DC casting model has been developed to simulate heat transfer, fluid flow, solidification, and thermally induced stress-strain during casting. A temperaturedependent HTC between the cooling water and the ingot surface, the cooling water flow rate, and the air gap were coupled in this model. An elasto-viscoplastic model developed on the basis of high-temperature mechanical testing was used to calculate the stress during casting. The model predicts the right trend of stress-strain development and can be used to predict cracking propensity during in DC casting of ingots.

\subsection{Prediction of Ingot Cracking Propensity}

\subsubsection{Introduction}

Two modeling approaches were taken in this project. One uses the integrated 3D model developed in this project to simulate solidification and crack formation in DC casting of ingots; the other uses thermodynamic simulation to predict the susceptibility to hot tearing in aluminum alloys.

The integrated 3D model couples heat transfer, fluid flow, microstructure evolution, and stressstrain formation. It is a highly sophisticated model but requires a long calculation time. The model predicts the right trend of stress and strain development in a DC cast ingot; thus, it can be used for evaluating parameters that affect hot tearing formation in the DC casting process.

One issue with the 3D model is related to the lack of heat transfer data and mechanical property data. It is well known that the HTCs are strongly affected by the water quality of the cooling jet. The physical and mechanical properties of an alloy are also strongly affected by the composition of the alloy and the trace element content. In an attempt to correlate ingot cracking propensity and the composition of an alloy, thermodynamic models were used based on the fundamental understanding of hot tearing formation at the end of solidification.

\subsubsection{Ingot Cracking Propensity Based on Stress-Strain Simulation}

The tendency to crack is higher if the thermal stress, $\sigma_{T}$, is large and closer to or higher than the strength of the alloy at temperatures close to the end of solidification. Strength, $\sigma$, is defined as the maximum stress exhibited by the material during a tensile test at a given temperature. The strength is a function of temperature and strain rate. In the ideal situation, when the thermal stress in the ingot can be accurately calculated, a cracking criterion would be simply

$$
\sigma_{T} \geq \sigma
$$

Since the 3D integrated model predicts the thermal stress only in the right magnitude, an ingot cracking index (ICI) needs to be defined to reflect ingot cracking propensity. An ICI was established based on the ratio of stress to strength; it is defined as

$$
I C I=\frac{\sigma_{T}}{\sigma} .
$$

The larger the ICI, the more likely the ingot is to crack during casting. Stress, $\sigma_{T}$, can be calculated using the 3D DC casting model for a specific set of casting parameters. The strength, 
$\sigma$, of the material can be obtained using the new technique developed in this project. (See Sect. 4.3 of this report.) The measured results can be fit as a function of temperature and strain rate to the following equation:

$$
\sigma=\left(10^{A \times T+B}\right) \times\left(\dot{\varepsilon}^{C \times T+D}\right)
$$

where $T$ is temperature, $\varepsilon$ is strain rate, and $A, B, C$, and $D$ are materials parameters.

In the DC casting model, the ICI can be calculated for every element of the solid model. Considering that ingot cracking usually occurs near the ingot surface and at the temperatures close to the solidus, a location close to the ingot surface at a temperature of $610^{\circ} \mathrm{C}(0.95$ solid fraction) was used for the ICI calculation. The ICI of this element is used as the index for evaluating parameters that affect cracking during DC casting.

Figure 4.6.1 shows the calculated stress and strain rate from the DC casting model and the strength of the alloy from Eq. (4.6.3) for various casting speeds. The x-axis is the normalized casting speed using the casting speed of the industrial ingot as 1 . The casting speed varies from 0.5 to 2.0 times that of the industrial casting speed. The results indicate that as casting speed increases, the calculated stress varies slightly but the strain rate decreases sharply. The strength of the alloy also decreases sharply with increasing casting speed because at a given temperature the strength is a function of strain rate.

Figure 4.6.2 shows the ICI for various casting speeds. The predicted ICI increases as the casting speed increases. The combination of an increase in stress and a decrease in strain rate as casting speed increases causes the ICI to increase as casting speed increases. This result is consistent with observations in industrial casting practice. The results indicate that the model may be able to predict cracking during DC casting. It is evident that a reduction in casting speed results in a significant reduction of cracking propensity.

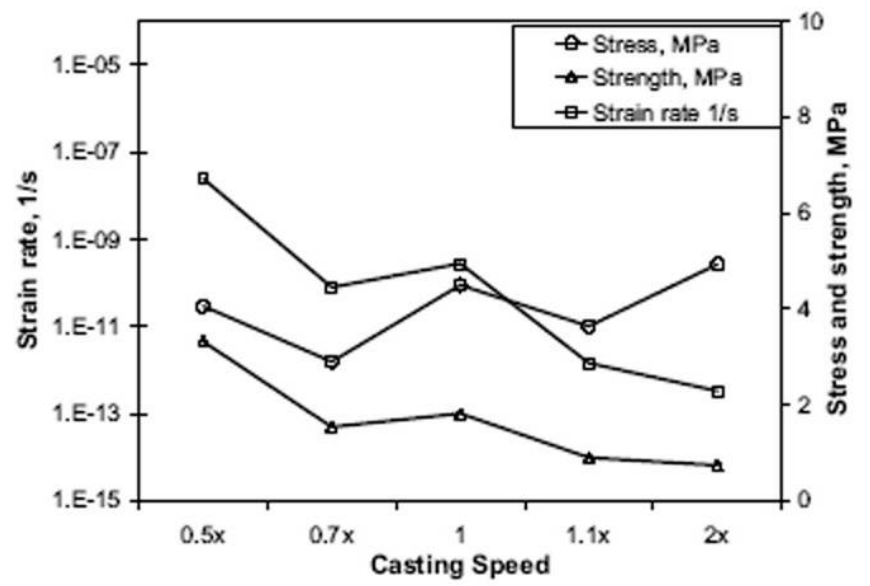

Fig. 4.6.1. Calculated stress, strain rate, and strength at a single specified location and a temperature of $610^{\circ} \mathrm{C}$ for a range of casting speeds. 


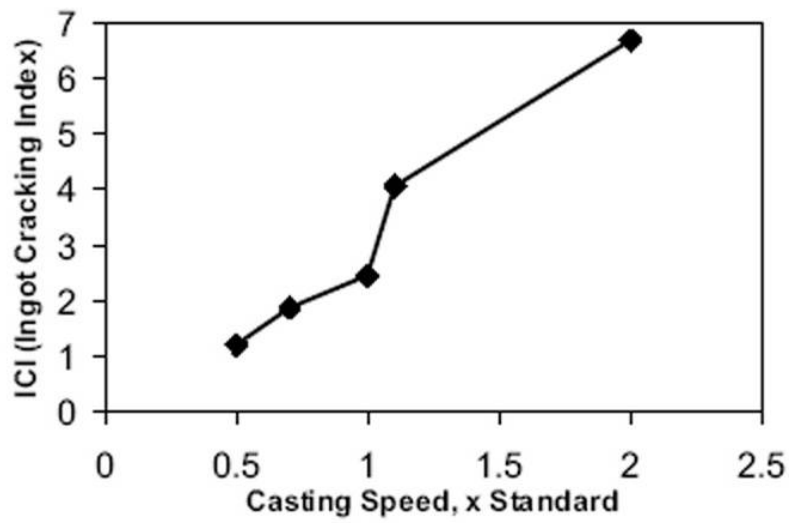

Fig. 4.6.2. The ingot cracking index calculated by the DC casting model for a range of casting speeds. 
In Fig. 4.6.2, the casting speed used by the industry is defined as 1, the speed at which the scrap rate due to hot tearing is about 4\%. An increase in casting speed leads to an increase in ICI, and thus increased cracking propensity and increased scrap rate due to hot tearing formation. On the other hand, a decrease in casting speed leads to decreased cracking propensity and decreased scrap rate due to hot tearing. Reducing casting speed seems to be one of the easy ways to reduce the scrap rate that is due to hot tearing.

\subsubsection{Hot Tearing Susceptibility: Thermodynamic Predictions}

\subsubsection{Background}

The predictions made using the 3D integrated model require extensive data on the physical and mechanical properties of the alloy as functions of temperature. These data often vary with varying compositions of alloys, and the alloy composition generally varies from melt to melt although the compositions are within the specification of the alloy. It has been observed for decades by the industry that cracking tendency varies from melt to melt. It is almost impossible to measure the physical and mechanical data as a function of composition and temperature.

The influence of alloy composition on the formation of hot hearing has been investigated extensively in binary alloys. Early research suggested that the hot tearing tendency of an alloy is related to the solidification range/interval of the alloy [35-39]. Hot tear tendency is greater in alloys with a larger solidification range than in those with a smaller solidification range. The formation of hot tears is associated with the ease of feeding the liquid into the regions where cracking occurs [40-42]. Hot tears can be healed if liquid can be fed into the cracks. Numerical simulations have been carried by Rappaz, Drezet, and Gremaud [43] to calculate the hot tearing tendency based on ease of liquid feeding. The simulation results also indicate that the hot tearing tendency of an alloy is closely related to the solidification range of the alloy.

In multicomponent alloys, the influence of composition on hot tearing formation becomes more complicated. Obviously, every element affects the solidification range of the alloy. The interaction between elements also influences the hot tearing tendency of the alloy. Han [44] examined the hot cracking susceptibility of a cobalt superalloy. He found that the cracking susceptibility is closely related to the solidus temperature of the alloy rather than to the solidification range, particularly in the case of an alloy containing elements that are highly segregated at the grain boundaries. The cracking tendency decreases with the increasing solidus temperature of the alloy. This is because the thermal and mechanical stress can be built up when the temperature in a casting reaches dendrite coherency point (at which a dendritic network forms). The coherency point occurs at a temperature corresponding to a solid fraction of about 0.3. Since solute segregation is not substantial at small solid affected much by the low-melting-temperature constituents (_solidus temperature is very sensitive to presence of segregating elements. Close to the solidus temperature, substantial stress can be built up in the casting, but there is still a small fraction of liquid present. The liquid will embrittle the alloy and thus form hot tearing in the region last to freeze. Aluminum alloy 3004 contains more than seven major alloying elements and a number of impurities. 
In order to understand the influence of elements on the hot tearing tendency of the alloy, ThermoCalc, a computational thermodynamic simulation package [20], and an aluminum alloy database, Al-3 [ $\stackrel{-\rho}{=}$ were used to calculate the liquidus and the solidus temperatures corresponding tl mposition of each melt. The solidification range of each melt was determined. The influence of composition on the solidus temperature of the alloy was investigated. Based on the thermodynamic simulations and the hot tearing information obtained under industrial conditions, the dependence of hot tearing on the solidification range of the alloy was assessed. The results indicate that the relationship between the hot tearing susceptibility and the solidification range of the alloy is not linear. Hot tearing is closely related to the solidus temperature of the alloy.

\subsubsection{Theory}

The theory was developed on the basis of the argument that the cracking tendency decreases with increasing solidus temperature for an alloy system. It is still difficult to determine the solidus temperature of an alloy without using thermodynamic simulation and the relevant database. However for a given alloy specification, the composition variations are rather small. Thus, the solidus temperature of the alloy can be estimated by [44]

$$
T_{S}=T_{0}+\sum_{i=1}^{N} S_{i} \Delta C_{i} \quad i=1 \ldots N
$$

where $i$ is the $i$ th alloying element, $N$ is the total number of solute elements in the alloy, $T_{s}$ is the solidus temperature of the alloy, and $T_{0}$ is the solidus temperature corresponding to the mean composition of the alloy. The terms $S_{i}$ and $\Delta C_{i}$ are defined as

$$
S_{i}=\frac{\partial T_{s}}{\partial C_{i}} \quad \text { at } \quad C_{i}=C_{0 i}
$$

and

$$
\Delta C_{i}=C_{i}-C_{0 i}
$$

where $C_{i}$ is the bulk concentration of the $i$ th element in the melt and $C_{0 i}$ is the mean concentration of the $i$ th element in the alloy specification. From its definition, $S_{i}$ is the solidus slop; its value can be calculated using thermodynamic simulations. The mean composition of the alloy can be found in any handbook on aluminum alloys. By carrying out a limited number of thermodynamic simulations to determine the $S_{i}$ values of each element at its mean concentration, the solidus temperature of the alloy with a known composition can be easily estimated using Eq. (4.6.4).

Equation (4.6.4) can also be rearranged as

$$
T_{S}-T_{0}=\sum_{i=1}^{N} S_{i} \Delta C_{i}
$$


The $\Delta C_{i}$ on the right-hand side of Eq. (4.6.7) is the composition variation of each melt with respect to the mean composition of the alloy. The left-hand side of this equation is the corresponding solidus temperature variation. For the purpose of discussing the effect of solute elements on the solidus temperature, it is sufficient to use the term on the right-hand side of Eq. (4.6.7).

When examining a single element in regard to the hot tearing susceptibility of an alloy, Eq. (4.6.7) can be rearranged as

$$
T_{S}-T_{0}-\sum_{i=1}^{N-1} S_{i} \Delta C_{i}=S_{N} \Delta C_{N}
$$

Either Eq. (4.6.7) or (4.6.8) can be used for discussing the hot tearing susceptibility of an alloy. The hot tearing tendency of an alloy decreases with increasing solidus erature.

\subsubsection{Industrial Data Analysis}

Over 50 compositions of commercial 5182 DC casting ingots and their cracking status were provided by industrial partners of this project. Thermodynamic simulations were carried out to determine the solidus temperature for each composition using ThermoCalc [20] and the aluminum database Al-3 [45]. The solidus slop of each element for this alloy was also calculated. For industrial applications, either Eq. (9.7) or (9.8) can be used to calculate the solidus temperature of the alloy if $\Delta C_{i}$ is known for each element in the melt/ingot.

Figure 4.6.3 shows the calculated solidus temperatures for each ingot vs the copper content in the ingot. The open circles represent the DC ingots that were not cracked. The other two symbols represent the DC ingots that either cracked during the start-up stage of DC casting or cracked later, resulting in large cracks. A border line can be drawn between the region that did not crack and the cracked region on the figure. The ingots with solidus temperatures higher than the border line experienced little cracking; the ingots with solidus temperatures below the border line were cracked. Another important feature shown by the graph in Fig. 4.6.3 is that cracking tends to occur in ingots with higher copper concentrations.

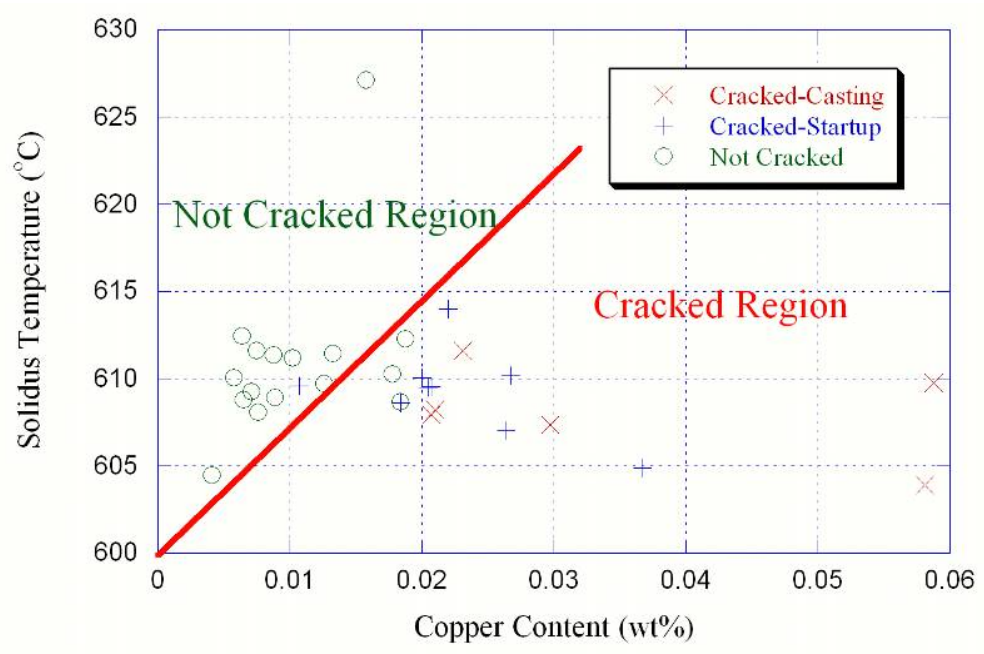


Fig. 4.6.3. Relationship between calculated solidus temperature and copper content in commercial $5182 \mathrm{DC}$ casting ingots. Cracking tends to occur at lower solidus temperatures and higher copper concentrations.

Another element that increases the hot tearing tendency of an aluminum 5182 DC casting ingot is zinc. Figure 4.6.4 shows the calculated solidus temperature vs the zinc concentration of the ingot. The open circles represent the DC ingots that did not crack. The other two symbols represent the DC ingots that either cracked during the start-up stage of DC casting or cracked later, forming large cracks. A border line can also be drawn between the region not cracked and the cracked region in Fig. 4.6.4. The ingots with solidus temperatures higher than the border line experienced little cracking; those with solidus temperature below the border line were cracked. The hot tearing susceptibility of the ingot increases with increasing zinc concentration in the ingot.

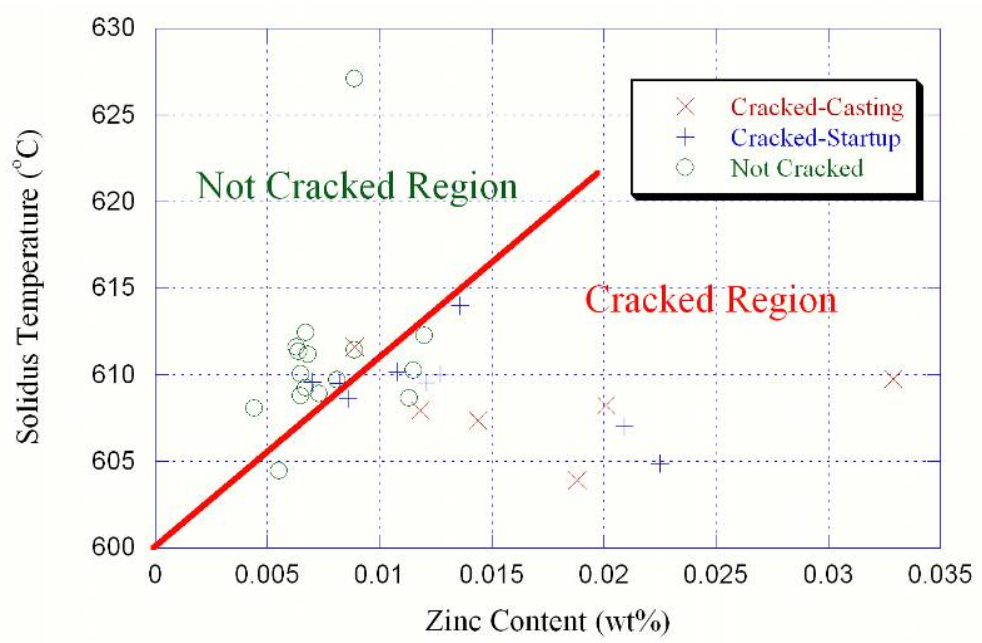

Fig. 4.6.4. Relationship between calculated solidus temperature and zinc content in commercial 5182 DC casting ingots. Cracking tends to occur at lower solidus temperature and higher zinc concentration.

Equations (4.6.7) and (4.6.8) and Figs. 4.6.3 and 4.6.4 are important to be used for minimizing $\underline{\underline{\underline{\underline{y}}}}$ ing in DC casting ingot for complex alloys such as aluminum alloys. These alloys contain -... - je number of elements such as $\mathrm{Mn}, \mathrm{Ti}, \mathrm{Mg}$, and $\mathrm{Si}$ in addition to $\mathrm{Cu}$ and $\mathrm{Zn}$. If the copper and zinc contents in a molten aluminum alloy are high, other elements can be altered so that the solidus temperature of the melt is high. As long as the solidus temperature of the melt is high, cracking will be unlikely to occur. These results provide a feasible way of reducing the cracking tendency before making the DC casting ingot, since chemical analysis can be done quickly before a casting is made. If the chemical composition analysis results indicate that the melt may have a low solidus temperature using Eqs. (4.6.7) or (4.6.8), the composition can be adjusted before making the casting.

In summary, ingot cracking susceptibility can be altered in various ways based on the results of this project. The casting speed is an important parameter that can be used for reducing the tendency of cracking formation. The scrap rate for DC casting of ingots can be reduced by 
decreasing the casting speed of the ingot. Hot tearing susceptibility is also sensitive to the composition of the alloy. High copper and zinc contents tend to increase the tendency toward cracking. However, other elements in the alloy can be altered to increase the solidus temperature of the alloy and thus reduce the cracking susceptibility of the ingot.

\section{Subject Inventions}

Intellectual property has been generated from this significant research effort. The intellectual property includes (1) the predictive DC casting model that is resident at Secat and at Oak Ridge National Laboratory (ORNL) and is accessible to the aluminum industry, (2) Wagstaff- and Aleris International-specific $\stackrel{-\rho}{=}$ and the relevant HTCs, and (3) a database of the thermophysical and mechani technology transfer of the project results, Secat research staff members actively participated in the modeling effort throughout the project period. A multiprocessor computer has been purchased for using the models. As a result, Secat has the required capabilities and expertise for transferring the developed technologies to the entire aluminum industry.

\section{Commercialization Possibilities}

Project participants have used several mechanisms to inform industries of the research results and advance commercialization: (1) incorporating the results into a commercial solidification package, ProCAST, so that the aluminum industry can obtain access to the project results; (2) launching Aluminum Answers, a Secat web site (http://www.secat.net/answers.php), partly for disseminating the latest research results to the aluminum industry; and (3) making presentations at national meetings organized by the Minerals, Metals, and Materials Society (TMS) and the American Society of Metals (ASM), and at industrial locations including Logan Aluminum and Aleris International. Aleris International is using the computational tools located at Secat to optimize the DC casting processes in its port plant. Companies who have expressed interest

in the research endeavor include the ind

\section{Plan for Future Collaboration}

This research project has successfully demonstrated that an increased understanding of microstructure formation and improved computational tools can be used for improving the DC casting process for aluminum 3004 and 5182 alloys. The results can lead to reduced scrap rates and increased energy savings. The project serves as a starting point for even more sophisticated models for the prediction of crack formation.

One of the breakthroughs of this project is having identified that an unfavorable combination of elements in alloys has a strong effect on crack formation. This is especially true when the alloy contains high copper and zinc contents. Cracking due to the presence of trace elements or due to an unfavorable combination of elements in alloys was not fully recognized in the past and was usually explained as being due to variations in water quality. One recommendation of the project 
team is that the industry should pay attention to controlling the composition of alloys to minimize crack formation.

For future research, the effect of trace elements deserves extensive research. Due to limitations in the thermodynamic database, this project was able to evaluate only some major elements ( $\mathrm{Al}, \mathrm{Cu}$, $\mathrm{Cr}, \mathrm{Fe}, \mathrm{Mg}, \mathrm{Mn}, \mathrm{Ni}, \mathrm{Si}, \mathrm{Ti}$, and $\mathrm{Zn}$ ). More research is needed in the future to examine impurity elements such as $\mathrm{Bi}, \mathrm{Ca}, \mathrm{Cd}, \mathrm{Li}, \mathrm{Na}, \mathrm{Pb}, \mathrm{Sb}, \mathrm{Sn}$, and $\mathrm{Sr}$ in order to fully asses the effect of composition on the cracking propensity of aluminum alloys.

\section{Conclusions}

A successful four-year project on the modeling and optimization of direct chill (DC) casting to reduce ingot cracking has been completed. The project involved close collaboration among private industries, national laboratories, and universities. During the four-year project, 16 quarterly meetings brought the industrial partners and the research team together for discussion of research results and research direction. The industrial partners provided guidance, facilities, and experience to the research team. The research team went to two industrial plants to measure temperature distributions in commercial 60,000-lb DC casting ingot. The collaborative research resulted in several major accomplishments or findings:

1. Surface cracks were shown to be a result of hot tearing rather than cold cracks, as was thought before this project. These cracks form on the surface of a DC cast ingot just above the impingement point of the secondary cooling water jets. The cracks form along dendrite and grain boundaries, where solute and impurity elements are highly segregated. This understanding led to the development of a new technique for determining the mechanical properties in the nonequilibrium mushy zone of alloys and to thermodynamic predictions of the hot tearing propensity of DC cast ingots.

2. The apparent heat transfer coefficient (HTC) at the ingot surface in the water cooling region during DC casting was determined on the basis of temperature measurements in commercial DC casting ingots and an inverse heat transfer analysis. HTCs were calculated as a function of temperature and time, and covered the different regimes of heat transfer expected during DC casting. The calculated values were extrapolated to include the effect of water flow rate. The calculated HTCs had a peak at around $200^{\circ} \mathrm{C}$, corresponding to the high heat transfer rates during nucleate boiling, and the profile was consistent with similar data published in the literature.

3. A new method, termed the reheating-cooling method (RCM), was developed and validated for measuring mechanical properties in the nonequilibrium mushy zones of alloys. The new method captures the brittle nature of aluminum alloys at temperatures close to the nonequilibrium solidus temperature, while specimens tested using the reheating method exhibit significant ductility. The RCM has been used for determining the mechanical properties of alloys at nonequilibrium mushy zone temperatures. Accurate data obtained during this project show that the metal becomes more brittle at high temperatures and high strain rates. 
4. The mechanical properties of the alloy at elevated temperatures were determined. Constitutive models relating the stress and strain relationship at elevated temperatures were developed. The experimental data fit the model well.

5. An integrated 3D DC casting model has been used to simulate heat transfer, fluid flow, solidification, and thermally induced stress-strain during casting. A temperaturedependent HTC between the cooling water and the ingot surface, cooling water flow rate, and air gap were coupled in this model. An elasto-viscoplastic model based on hightemperature mechanical testing was used to calculate the stress during casting. The 3D integrated model can be used for the prediction of temperature, fluid flow, stress, and strain distribution in DC cast ingots.

6. The cracking propensity of DC cast ingots can be predicted using the 3D integrated model as well as thermodynamic models. Thus, an ingot cracking index based on the ratio of local stress to local alloy strength was established. Simulation results indicate that cracking propensity increases with increasing casting speed. The composition of the ingots also has a major effect on cracking formation. It was found that copper and zinc increase the cracking propensity of DC cast ingots.

The goal of this Aluminum Industry of the Future ( industry in reducing the incidence of stress cracks i. - castings from a current level of 5\% down to 2\%. This could lead to energy savings in excess of 6 trillion Btu by the year 2020 given full-scale industrial implementation of the results. The project indicates that ingot cracking can be minimized by reducing the casting speed or by controlling the composition of the alloy. These results can be incorporated into industrial applications to achieve significant energy savings.

\section{Acknowledgment}

This report is based upon work supported by the U.S. Department of Energy, Energy Efficiency and Renewable Energy, Industrial Technologies Program, Aluminum Industry of the Future, under Solicitation No. DE-PS07-99ID13824 with the award made to Secat, Inc.

Research was sponsored by the U.S. Department of Energy, Office of Energy Efficiency and Renewable Energy, Industrial Technologies Program, under contract DE-AC05-00OR22725 with UT-Battelle, LLC.

The significant accomplishments of this project would not have been achieved without access to the excellent facilities of Oak Ridge National Laboratory (ORNL); Wagstaff, Inc.; Logan Aluminum, Inc,; Commonwealth Aluminum; and Secat, Inc., made available through Peter Angelini, H. Wayne Haden, R. Wagstaff, Michael K. Anderson, Lee J. Davis, D. Spainhower, James McNeil, Gyan Jha, Tony Phelps, Zhong Li, Joe Tessandori, and S. K. Das. The principal investigator of this project also realize that the significant accomplishments of this endeavor could not have been achieved except through the dedicated and excellent contributions of the other project research team members from ORNL, the University of Kentucky, the Albany 
Research Center, Argonne National Laboratory, and Secat, composed of Q. Han, S. Viswanathan, Adrian Sabau, Kozo Saito, Marwan Khraisheh, Mohamed H. Hassan, Kazunori Kuwana, Shridas Ningileri, Zhengdong Long, John Clark, and John Hyrn. The authors wish to thank Dr. Peter Angelini for reviewing the document, and Carolyn I. Moser for editing and preparing the document.

\section{References}

1. W. Scheider and E. K. Jensen, pp. 931-936 in Light Metals 1990, ed. C. M. Bicker (Warrendale, Penn.: TMS-AIME, 1990).

2. E. K. Jensen and W. Schneider, pp. 937-943 in Light Metals 1990, ed. C. M. Bickert (Warrendale, Penn.: TMS-AIME, 1990).

3. W. Droste and W. Schneider, pp. 945-951 in Light Metals 1991, ed. E. L. Rooy (Warrendale, Penn.: TMS-AIME, 1991).

4. D. Mortensen, Metallurgical and Materials Transactions B 30 (1999): 119-133.

5. J. B. Wiskel and S. L. Cockcroft, Metallurgical Transactions B 27 (1996): 119-

6. J. B. Wiskel, and S. L. Cockcroft, Metallurgical Transactions B 27 (1996): 129-140.

7. J. Mathew and H. D. Brody, pp. 244-249 in Proceedings of the International Conference on Solidification and Casting of Metals, ed. A. Nicholson, University of Shieffield, Shieffield, England, July 1977 (London: The Metals Society, 1979).

8. B. Hannart, F. Cialti and R. V. Schalkwijk, pp.879-887 in Light Metals 1994, ed. U. Mannweiler, (Warrendale, Penn.: TMS-AIME, 1994).

9. H. G. Fjaer and A. Mo, Metallurgical Transactions B 21 (1990): 1049-1061.

10. J.-M. Drzet and M. Rappaz, Metallurgical and Materials Transactions A 27 (1996): 3214-3225.

11. K. Nakayama, M. Kinefuchi, and K. Tsutsumi, pp. 915-922 in Modeling of Casting, Welding, and Advanced Solidification Processes-VIII, ed. B. G. Thomas and C. Beckermann (Warrendale: Penn.: TMS, 1998).

12. P. Wisniewski and H. D. Brody, p. 273 in Modeling of Casting, Welding, and Advanced Solidification Processes - V, ed. M. Rappaz, M. R. Ozgu, and K. W. Mahin (Warrendale, Penn.: TMS-AIME, 1990).

13. B. G. Thomas, ISIJ International 35 (1995): 737-743.

14. M. Bellet, F. Decultieux, M. Menai, F. Bay, C. Levaillant, J. L. Chenot, P. Schmidt, and I. L. Svensson, Metallurgical and Materials Transactions B 29 (1996): 81-99.

15. V. K. Dhir, “Boiling Heat Transfer,” Annual Review of Fluid Mechanics 30 (1998): 365-401.

16. Aluminum Industry Technology Roadmap (Washington, D.C.: The Aluminum Association, May 1997).

17. K. M. Chang and B. Kang, Journal of the Chinese Institute of Engineers 22 (1999): 27-42.

18. J. M. Drezet et al., Metallurgical and Materials Transactions A 31 (2000): 1627-1634.

19. ProCAST, User's Manual \& Technical Reference.

20. B. Sundman, B. Jansson, and J. O. Andersson, Calphad 9 (1985): 153-190. 
21. Al- $3^{\mathrm{TM}}$, AEA Technology Engineering Software, Inc., 2000 Oxford Drive, Suite 610, Bethel Park, PA 15102, USA, 2000.

22. J. F. Grandfield and P. T. McGlade, Materials Forum 20 (1996): 29-51.

23. W. S. Pellini, Foundry 80 (1952): 125-133.

24. J. A. Williams and A. R. E. Singer, Journal of Institute of Metals 96 (1968): 5-12.

25. M. G. Chu and D. A. Granger, Materials Science Forum 217-222 (1996): 1505-1510.

26. C. S. Lin and J. A. Sekhar, Journal of Materials Science 29 (1994): 3637-3642.

27. T. Nakagawa, P. Suvanchai, T. Okane, and T. Umeda, Materials Science Forum 215-216 (1996): 377-384.

28. S. Instone, D. St. John, and J. Grandfield, International Journal of Cast Metals Research 12 (2000): 441-456.

29. G. X. Liu and W. Dahl, Steel Research 60 (1989): 221-229.

30. D. J. Seol, Y. M. Won, K. H. Oh, Y. C. Shin, and C. H. Yim, ISIJ International 40 (2000): 356-363.

31. B. Magnin, L. Maenner, L. Katgerman, and S. Engler, Materials Science Forum 217-222 (1996): 1209-1214.

32. A. J. Duncan, Q. Han, and S. Viswanathan, Metallurgical and Materials Transactions B 30 (1999): 745-750.

33. J. Sengupta, D. Maijer, M.A. Wells, S.L. Cockcroft, A. Larouche, Light Metals 2003, ed P.N. Crepeau, TMS, Warrendale, PA, 00. 841-847.

34. C. Bagnoud and M. Plata, Modeling of Casting, Welding and Advanced Solidification Processes IX, ed. P.N. Sahm et al, (Shaker-Verlag, Aachen, Germany), 2000, 753-760.

35. J. Vero, Metal Industry 48 (1936): 431-439.

36. A. R. E. Singer and S. A. Cotterell, Journal of the Institute of Metals 73 (1946): 33-54.

37. W. S. Pellini, Foundry 80 (1952): 124-133.

38. H. F. Bishop, C. G. Ackerlind, and W. S. Pellini, Transactions of the American Foundry Society 60 (1952): 818-833.

39. J. C. Borland, British Welding Journal, August 1960, pp. 508-512.

40. T. W. Clyne and G. J. Davies, British Foundryman 74 (1981): 65-73.

41. Y. F. Guven and J. D. Hunt, Cast Metals 1 (1988): 104-111.

42. J. Campbell, p. 219 in Casting (Oxford, UK: Butterworth-Heinemann, 1991).

43. M. Rappaz, J. M. Drezet, and M. Gremaud, Metallurgical and Materials Transactions A 30 (1999): 449-455.

44. Q. Han, AFS Transactions, 2004, Paper 4-62.

45. N. Saunders, Themotech Tech. Ltd, Surrey Technology Center, Surrey Research Park, Guildford, UK, 1999. 


\section{DISTRIBUTION}

Internal Distribution

1. Craig A. Blue, 4508, MS-6083

2. P. J. Hadley, 4500S, MS-6161

3. Q. Han, 4508, MS-6083

4. Ronald D. Ott, 4508, MS-6083

5. Office of Technical Information \& Classification, 4500N, MS-6254

6. A.E. Pasto, 4515, MS-6062

7. Sharon M. Robinson, 4500N, MS-6181

8. T.M. Rosseel, 4500S, MS-6138

9. A. Sabau, 4508, MS-6083

10. V.K. Sikka, 4508, MS-6083

11. P.S. Sklad, 4515, MS-6065

12. Steven J. Zinkle, 4500S, MS-6132

\section{External Distribution}

13. P.A. Carpenter, 4500 N, MS-6269

14. John A. Clark, Albany Research Center, 1450 Queen Avenue, SW., Albany, OR 97321

15. DOE-WFO, 1000, MS-6396

16. Subodh K. Das, Secat, Inc., 1505 Bull Lea Blvd, Lexington, KY 40511

17. Ehr-Ping HuangFu, 1000 Independence Ave. SW, EE-2F Washington, DC 20585

18. John N. Hyrn, Argonne National Laboratory, 9700 South Cass Avenue, Bldg 362, Argonne, IL 60439-4815

19. Marwan Khraisheh, Dept. of Mech. Eng., Univ. of Kentucky, CRMS Bldg, Lexington, KY 40506-0108

20. Zhong Li, Aleris International, 1505 Bull Lea Blvd, Lexington, KY 40511

21. Shridas Ningileri, Secat, Inc., 1505 Bull Lea Blvd, Lexington, KY 40511

22. Kozo Saito, Dept. of Mech. Eng., Univ. of Kentucky, 514B CRMS Bldg, Lexington, KY 40506-0108

23. S. Viswanathan, Dept. of Met. And Mat. Eng., Univ. of Alabama, Box 870202, Tuscaloosa, AL 35487-0202

24. Zhengdong Long, 1505 Bull Lea Blvd, Lexington, KY 40511 